\title{
Effects of high temperature on photosynthesis and related gene expression in poplar
}

\author{
Yuepeng Song ${ }^{1,2 \dagger}$, Qingqing Chen ${ }^{1,2 \dagger}$, Dong $\mathrm{Ci}^{1,2}$, Xinning Shao ${ }^{1,2}$ and Deqiang Zhang ${ }^{1,2^{*}}$
}

\begin{abstract}
Background: High temperature, whether transitory or constant, causes physiological, biochemical and molecular changes that adversely affect tree growth and productivity by reducing photosynthesis. To elucidate the photosynthetic adaption response and examine the recovery capacity of trees under heat stress, we measured gas exchange, chlorophyll fluorescence, electron transport, water use efficiency, and reactive oxygen-producing enzyme activities in heat-stressed plants.

Results: We found that photosynthesis could completely recover after less than six hours of high temperature treatment, which might be a turning point in the photosynthetic response to heat stress. Genome-wide gene expression analysis at six hours of heat stress identified 29,896 differentially expressed genes (15,670 up-regulated and 14,226 down-regulated), including multiple classes of transcription factors. These interact with each other and regulate the expression of photosynthesis-related genes in response to heat stress, controlling carbon fixation and changes in stomatal conductance. Heat stress of more than twelve hours caused reduced electron transport, damaged photosystems, activated the glycolate pathway and caused $\mathrm{H}_{2} \mathrm{O}_{2}$ production; as a result, photosynthetic capacity did not recover completely.

Conclusions: This study provides a systematic physiological and global gene expression profile of the poplar photosynthetic response to heat stress and identifies the main limitations and threshold of photosynthesis under heat stress. It will expand our understanding of plant thermostability and provides a robust dataset for future studies.
\end{abstract}

Keywords: Photosynthesis, Gene expression profile, Heat stress, Populus simonii

\section{Background}

Photosynthesis converts light energy into usable chemical energy for plant growth and development [1]. As the most intricate physiological process in plants, photosynthesis incorporates numerous components, including $\mathrm{CO}_{2}$ reduction pathways, photosynthetic photosystems and the electron transport system [2]. Among these, Photosystem II (PSII) has been described as the most heat-sensitive component of the photosynthetic apparatus [3]. In Populus euphratica, heat stress causes a decrease in PSII abundance and an increase of Photosystem I (PSI); it also induces photosynthetic linear

\footnotetext{
*Correspondence: DegiangZhang@bjfu.edu.cn

${ }^{\dagger}$ Equal contributors

'National Engineering Laboratory for Tree Breeding, College of Biological Sciences and Technology, Beijing Forestry University, No. 35, Qinghua East Road, Beijing 100083, P. R. China

${ }^{2}$ Key Laboratory of Genetics and Breeding in Forest Trees and Ornamental Plants, College of Biological Sciences and Technology, Beijing Forestry University, No. 35, Qinghua East Road, Beijing 100083, P. R. China
}

electron flow [4]. Sharkey et al. (2005) reported that reduction of plastoquinone and cyclic electron flow can be stimulated by moderate heat stress [5]. Moderate heat stress also causes a reduction in Rubisco activities. The Rubisco oxygenase side reaction promotes the production of $\mathrm{H}_{2} \mathrm{O}_{2}$, which can be toxic to plant cells.

Transitory or constant high temperature causes morphological, physiological, and biochemical changes that reduce photosynthesis and thus limit plant growth and productivity $[2,6]$. Moderate heat stress causes a reversible reduction of photosynthesis; increased heat stress causes irreversible damage to the photosynthetic apparatus, resulting in greater inhibition of plant growth [7]. A report from the Intergovernmental Panel on Climatic Change [8], predicts that the Earth's climate will warm by $2-4^{\circ} \mathrm{C}$ by the end of the 21st Century [9]. Therefore, a fundamental understanding of the response of photosynthetic physiology and related gene expression under heat stress may help to improve the thermostability of 
plants and limit the adverse effects of climate change on crop yield.

Many studies have examined the effects of stress on the electron transport system, photosystems, pigments, photosynthesis-related enzyme activities, gas exchange and chlorophyll fluorescence in plants $[10,11]$. These studies have mostly focused on the adaptive responses of plants to heat stress, but less attention has been paid to the recovery capacity of plants under stress. Trees, with their long lifetimes, must periodically contend with fluctuating environmental conditions. Thus, they have evolved specific physiological mechanisms to adapt to natural changes in environmental conditions [12]. Analysis of the adaption response and recovery capacity of trees to heat stress will expand our understanding of thermostability in all plants.

Most adaptive responses function, at least in part, through control of gene expression; therefore, heatresponsive transcription factors might play a critical role in abiotic stress responses [13]. Multiple genes interacting with each other and with the environment act in the responses to heat stress [2]. bZIP (Basic Leucine Zipper) transcription factors have broad functions in plant biotic and abiotic stress responses, light signaling, and abscisic acid (ABA) signaling [14]. NAC (NAM, ATAF1/2, CUC2) family transcription factors have been implicated in the activation of expression of EARLY RESPONSIVE TO DEHYDRATION STRESS 1 (ERD1) [15] and are predominantly induced by abiotic stress in guard cells [16]. $M Y B$ gene family members function in ABA signaling, and in jasmonic acid-related gene expression, indicating that they affect crosstalk between abiotic and biotic stress responses [17]. CBF/DREB1 (C Repeat Binding Factor/ Drought Response Element Binding 1) family members activate the expression of genes related to the production of osmoprotectants and antioxidants and their expression is quickly and transiently induced by abiotic stress [13]. The numbers and expression of genes involved in regulation of photosynthesis in trees in response to heat stress remains unclear. Therefore, it is extremely important to identify and analyze genes involved in high temperature tolerance in trees.

The advantages of using members of the poplar genus (Populus) as genomic models for tree molecular biology have been extensively reported $[18,19]$. Among Populus species, $P$. simonii shows remarkable survival capability, even in extreme temperatures $\left(-41^{\circ} \mathrm{C}\right.$ to $\left.+43^{\circ} \mathrm{C}\right)$ and other abiotic stresses [20]. Recent work reported the genome-wide gene expression profiles of the $P$. simonii responses to chilling and drought stress [21,22]. However, information on the genome-wide transcriptome response of $P$. simonii to heat stress remains limited. Therefore, we selected $P$. simonii to examine the mechanisms of heat-tolerance in poplar. Our study presents a systematic investigation of differentially expressed genes in heat-stressed P. simonii. Furthermore, these differentially expressed genes may be suitable targets for biotechnological manipulation to improve heat tolerance in poplar and other species.

\section{Methods}

\section{Plant materials and treatments}

P. simonii samples were collected from Huzhu County of Qinghai Province, northwest China. The 1-year-old plant material was propagated from branches of adult mother plants. The material was planted in pots with inner size of $10 \mathrm{~cm}$ in height and $15 \mathrm{~cm}$ in diameter, containing a potting mix of a commercial medium and perlite at a ratio of 3:1. These seedlings were watered regularly with a nutrient solution.

Poplar 'QL9' were maintained under natural light conditions in an air-conditioned greenhouse under a $25 \pm 1^{\circ} \mathrm{C}$, $50 \% \pm 1$ relative humidity and $12 \mathrm{~h}$ day/ night regime [23]. Fifty clones were propagated from mother plant 'QL9'. Among these, fifteen annual clones of approximately the same size and height were exposed to constant high temperature treatment $\left(42^{\circ} \mathrm{C}\right)$ for three hours, six hours, twelve hours and twenty-four hours. Clones growing at constant room temperature $\left(25^{\circ} \mathrm{C}\right)$ were used as the control group. Relative humidity set to $50 \% \pm 1$ was held constant during measurements [24]. Each treatment group, including the control group, contained three replicate clones. Gas exchange and chlorophyll a fluorescence transients were measured under stress conditions. To detect the recovery of photosynthesis under heat stress, each treatment group was returned to room temperature after $24 \mathrm{~h}$, then gas exchange and chlorophyll a fluorescence transients were measured again. To confirm whether candidate genes were generally temperature-responsive, constant chilling stress $\left(4^{\circ} \mathrm{C}\right.$, six hours) were performed. Constant $1250 \mu \mathrm{molm}^{-2} \mathrm{~s}^{-1}$ PPFD light conditions were provided during treatment. Leaves were collected from treatment groups and the control group for physiological and gene expression analysis, then immediately frozen in liquid nitrogen and stored at $-80^{\circ} \mathrm{C}$ until analyzed.

\section{Photosynthetic rate measurements}

The fourth fully expanded leaf, from each of three clones in each treatment was harvested for photosynthetic rate measurements using the portable photosynthesis system (LI-6400; Li-Cor Inc., Lincoln, NE, USA) from 18 to 24 August 2013. To achieve full photosynthetic induction, all samples were illuminated with saturated photosynthetic photon flux density (PPFD) provided by a light-emitting diode (LED) light source for $30 \mathrm{~min}$ before measurements. Subsequently, net photosynthetic rate (Pn), transpiration rate $(\mathrm{Tr})$, intercellular $\mathrm{CO}_{2}$ concentration $(\mathrm{Ci})$ and stomatal conductance (Gs) were measured simultaneously. 
All parameters for measurement were as described by Chen et al. (2010) [25]. Intrinsic water use efficiency (iWUE) was calculated from the ratio of Pn and Tr.

\section{Measurement of physiological and biochemical characteristics}

Superoxide dismutase (SOD), peroxidase (POD), catalase (CAT) and malondialdehyde (MDA) were measured as described by Giannopolitis and Ries (1977), Bestwick et al. (1998), Carrill et al. (1992) and Dhindsa et al. (1981), respectively, and measured by absorption photometry using a spectrophotometer. The details were according to Song et al. (2013) [26-30]. Ascorbate peroxidase (APX) activity assays were according to the method of Nakano and Asada (1981) [31]. At $290 \mathrm{~nm}$, absorbance of the reaction was monitored using a spectrophotometer. The extinction coefficient of ascorbate was used for calculating APX enzyme activity.

\section{$\mathrm{H}_{2} \mathrm{O}_{2}$ analysis}

Endogenous $\mathrm{H}_{2} \mathrm{O}_{2}$ levels were detected by measuring luminol-dependent chemiluminescence according to the method described by Dat et al. (1998) and the $\mathrm{H}_{2} \mathrm{O}_{2}$ specific fluorescent probe 2',7'-Dichlorodihydrofluorescein diacetate (H2DCF-DA, green) (Molecular Probes, Eugene, OR, USA, prepared in a 2-(N-morpholino) ethane sulfonic acid (MES)-KCl buffer, $\mathrm{pH}$ 5.7) [32]. MES-KCl buffer solution was used for washing the leaves sampled from treated poplar. After that, all samples were incubated in the buffer solution containing $50 \mu \mathrm{M}$ H2DCF-DA for $40 \mathrm{~min}$ at room temperature. Leaves were examined using a Leica SP5 confocal microscope (Leica Microsystems GmbH, Wetzlar, Germany) under the following settings: excitation $=488 \mathrm{~nm}$, emission $=510-$ $530 \mathrm{~nm}$, frame $512 \times 512$.

\section{Chlorophyll fluorescence measurement}

Chlorophyll fluorescence was measured using the LICOR 6400 system, according to the recommended procedures in the users' manual (LICOR Biosciences, Inc., Lincoln, NE). The fourth fully expanded leaves were darkacclimated in the LI-6400XT leaf chamber for $20 \mathrm{~min}$ at $28 \pm 0.1^{\circ} \mathrm{C}$ prior to measuring minimum fluorescence (Fo) and maximum fluorescence (Fm), which was followed by $20 \mathrm{~min}$ of light acclimation at $550 \mu \mathrm{mol} \mathrm{m} \mathrm{m}^{-2}$ PPFD prior to ramping up temperature [33]. Variable fluorescence $(\mathrm{Fv})$ in the dark-adapted state was calculated as: $\mathrm{Fv}=\mathrm{Fm}$-Fo. The fluorescence chamber provided a one-second pulse of continuous red light $(3000 \mu \mathrm{mol}$ photons $\mathrm{m}^{-2} \mathrm{~s}^{-1}$ maximum light intensity) for illumination. Maximum quantum efficiency of PSII was calculated using the formula: $\mathrm{Fv} / \mathrm{Fm}=(\mathrm{Fm}-\mathrm{Fo}) / \mathrm{Fm}$. Subsequently, the minimum fluorescence $\left(F^{\prime} \mathrm{o}\right)$, variable fluorescence $\left(\mathrm{F}^{\prime} \mathrm{v}\right)$ and maximum fluorescence $\left(\mathrm{F}^{\prime} \mathrm{m}\right)$ in the light-adapted state were measured. Photochemical quenching (qP) was calculated as: $\mathrm{qP}=\left(\mathrm{F}^{\prime} \mathrm{m}-\mathrm{Fs}\right) /\left(\mathrm{F}^{\prime} \mathrm{m}-\mathrm{F}^{\prime} \mathrm{o}\right)$ using the steady state parameter (Fs). Simultaneously, the relative quantum yield of PS II ( $\varphi$ PSII $)$ was calculated as: $\varphi$ PSII $=\left(F^{\prime} m-F s\right) / F^{\prime} m$ and the electron transport rate (ETR) was estimated as: $\mathrm{ETR}=\mathrm{PPFD} \times \varphi \mathrm{PSII} \times 0.85 \times 0.5$.

\section{RNA extraction, cDNA synthesis, Microarray Hybridization} and Data Analysis

RNAeasy Plant mini kit (Qiagen, Hilden, Germany) and Super-Script First-Strand Synthesis system (Invitrogen) were used for total RNA extraction and cDNA synthesis, respectively. The details were according to the method described by Song et al. (2013) [30]. To identify differentially expressed genes under heat stress, we used the six-hour treatment group for microarray expression profiling. Fresh tissue leaf samples were collected from the three independent $P$. simonii, as biological replicates, for RNA extraction. The process of amplification, labeling, purification and hybridization were performed at the Shanghai Bio Institute using the Affymetrix GeneChip Poplar Genome Array (contained 6, 1314 probe). Gene set enrichment analysis was performed using AgriGO analysis tools (http:// bioinfo.cau.edu.cn/agriGO/). Annotation information was obtained from GenBank (http://www.ncbi.nlm.nih.gov/ genbank/) and The Kyoto Encyclopedia of Genes and Genomes (KEGG, http://www.genome.jp/kegg).

\section{Quantitative Real-time Polymerase Chain Reaction (PCR) verification}

Quantitative PCR (qPCR) was performed using the TaKaRa ExTaq R PCR Kit, SYBR green dye (TaKaRa, Dalian, China) and a DNA Engine Opticon 2 machine (MJ Research). The qPCR program included an initial denaturation at $94^{\circ} \mathrm{C}$ for $5 \mathrm{~min}$, followed by 40 cycles of $30 \mathrm{~s}$ at $94^{\circ} \mathrm{C}, 30 \mathrm{~s}$ at $58^{\circ} \mathrm{C}$, and $30 \mathrm{~s}$ at $72^{\circ} \mathrm{C}$, and a final melt-curve $70-95^{\circ} \mathrm{C}$. The melting curve was used to check the specificity of the amplified fragment. All reactions were carried out in triplicate for technical and biological repetitions of three individuals. The generated real-time data were analyzed using the Opticon Monitor Analysis Software 3.1 tool. Specific primer sets were designed to target the $3^{\prime}$ untranslated region (UTR) of each gene using Primer Express 3.0 software (Applied Biosystems). The real-time PCR primer pairs are shown in Additional file 1. The efficiency of the primer sets was calculated by performing real-time PCR on several dilutions of first-strand cDNAs. Efficiencies of the different primer sets were similar. The specificity of each primer set was checked by sequencing PCR products [34]. The results obtained for the different tissues analyzed were standardized to the transcript levels for PtACTIN (Additional file 2). 


\section{Statistical analysis}

One-way ANOVA was performed using the R software, and significant differences between different stress treatments were determined through Fisher's Least Significant Difference (LSD) test. Differences were considered statistically significant when $\mathrm{P}<0.01$. Differentially expressed genes (fold change $>2$ or $<0.5 ; P<0.001$ ) were identified. The parameters of fold change analysis data filtered and minimum false discovery rate were calculated according to Song et al. (2013) [21].

\section{Results}

\section{Response of the photosynthetic rate to heat stress}

To examine the effects of high temperature on poplar photosynthesis, we measured the dynamic Pn, Ci, Gs, Tr, and iWUE over a time course of high temperature treatment ( 0 h, 3 h, 6 h, 12 h, 24 h) (Figure 1A-E). At three hours, Pn, Gs, $\mathrm{Tr}$ and $\mathrm{Ci}$ were significantly lower in heat-treated plants than in control plants, but iWUE was significantly higher. At six hours, Pn, Gs and Tr increased slightly in heat-treated plants, but were significantly less than in control plants. Also at six hours, $\mathrm{Ci}$ decreased to its minimum value and iWUE increased dramatically to a peak. After six hours, Pn, Gs, Tr and iWUE decreased from twelve to twenty-four hours. By contrast, Gi showed a rising trend at subsequent time points.

We also detected photosynthetic recovery after heat stress at different time points in plants that had been returned to room temperatures. Our results showed that photosynthetic rate could be completely recovered after three or six hours of high temperature treatment. However, after $12 \mathrm{~h}$ and $24 \mathrm{~h}$ heat stress, the photosynthetic rate recovered to only $68.8 \%$ and $45.2 \%$ of control group levels, respectively. Chlorophyll fluorescence reflects the photodamage or photoprotection-related effects of environmental stress on photosynthetic systems [35]. To examine this, we measured Fo, the ratio of variable and maximal fluorescence $(\mathrm{Fv} / \mathrm{Fm})$, electron transport rate (ETR) and fluorescence quenching coefficient $(q \mathrm{P})$ (Figure 2A-E). Compared with the control group, Fo, Fv/Fm, F'v/F'm ETR and $q \mathrm{P}$ were not significantly changed after three and six hours heat stress. After that, Fv/Fm, F'v/F'm, ETR and $q \mathrm{P}$ dramatically decreased at 12 and $24 \mathrm{~h}$, but Fo increased significantly and constantly.
A
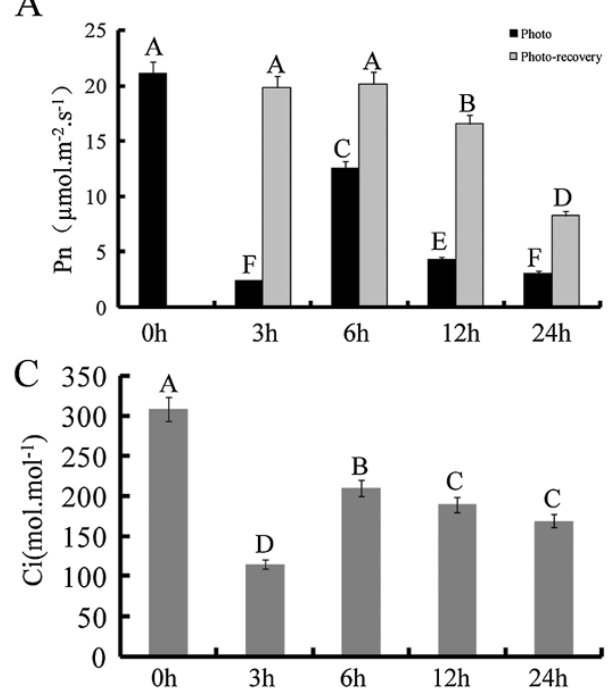

$\mathrm{E}$

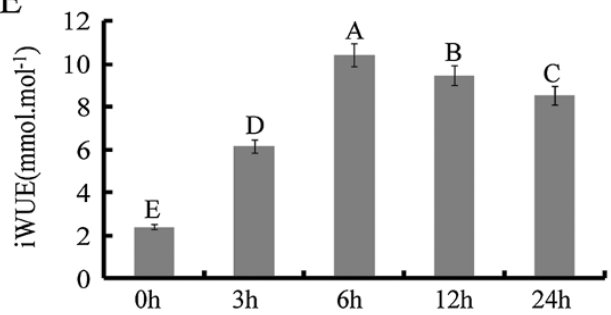

$\mathrm{B}$
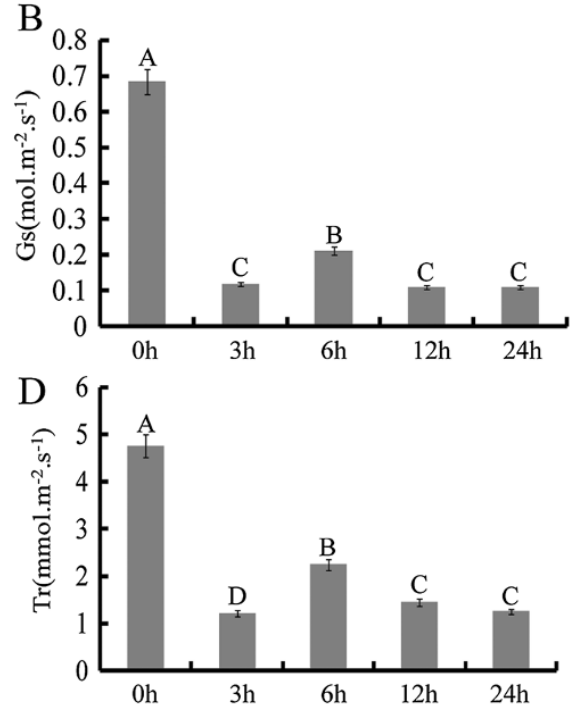

Figure $\mathbf{1}$ Changes in gas exchange at high temperatures. A: Pn represents photosynthetic rate; $\mathbf{B}$ : Gs represents stomatal conductance; C: Ci represents intercellular $\mathrm{CO}_{2}$ concentration; $\mathbf{D}$ : Tr represents transpiration rate; $\mathbf{E}$ : iWUE represents intrinsic water use efficiency. Oh indicates the control group without high temperature treatment. 3-24h indicates different times of exposure to heat stress. Error bars represent standard error. Different letters on error bars indicate significant differences at $P<0.01$. Symbols are the same in the following figures. 


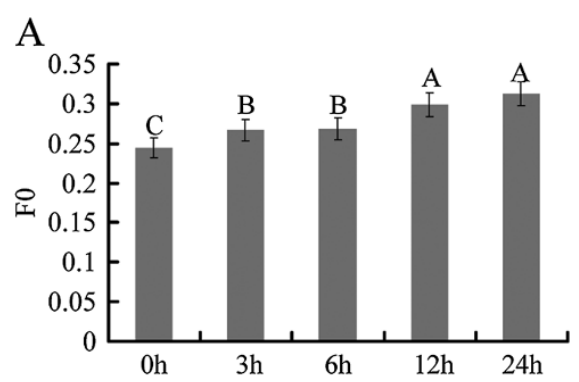

$\mathrm{C}$

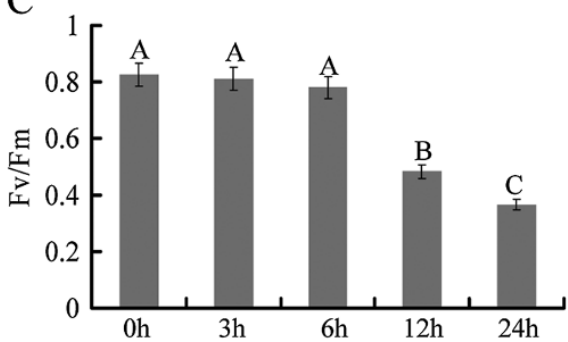

$\mathrm{E}$

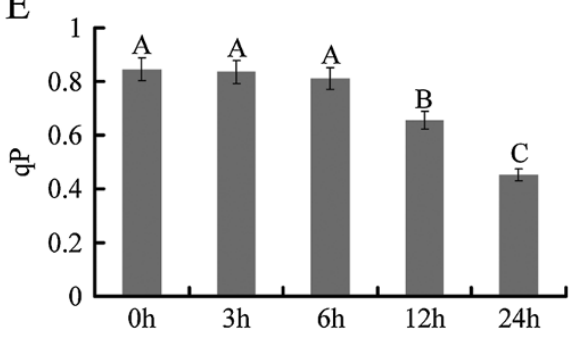

B

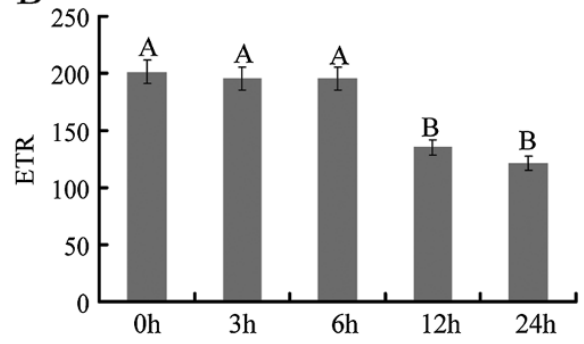

$\mathrm{D}$

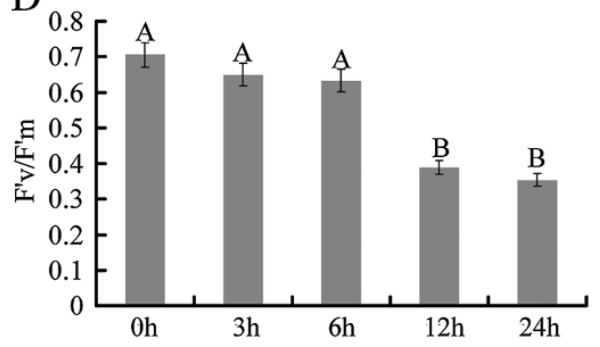

Figure $\mathbf{2}$ Changes in chlorophyll fluorescence at high temperatures. A: Fo represents minimum fluorescence. B: ETR represents electron transport rate. C: Fv/Fm represents the ratio of variable to maximal chlorophyll fluorescence. D: F' $v / F^{\prime} m$ represents fluorescence in the light ratio. E: qP represents photochemical quenching. $0 \mathrm{~h}$ indicates the control group without high temperature treatment. 3-24 $\mathrm{h}$ indicates different times of exposure to heat stress. Error bars represent standard error. Different letters on error bars indicate significant differences at $P<0.01$.
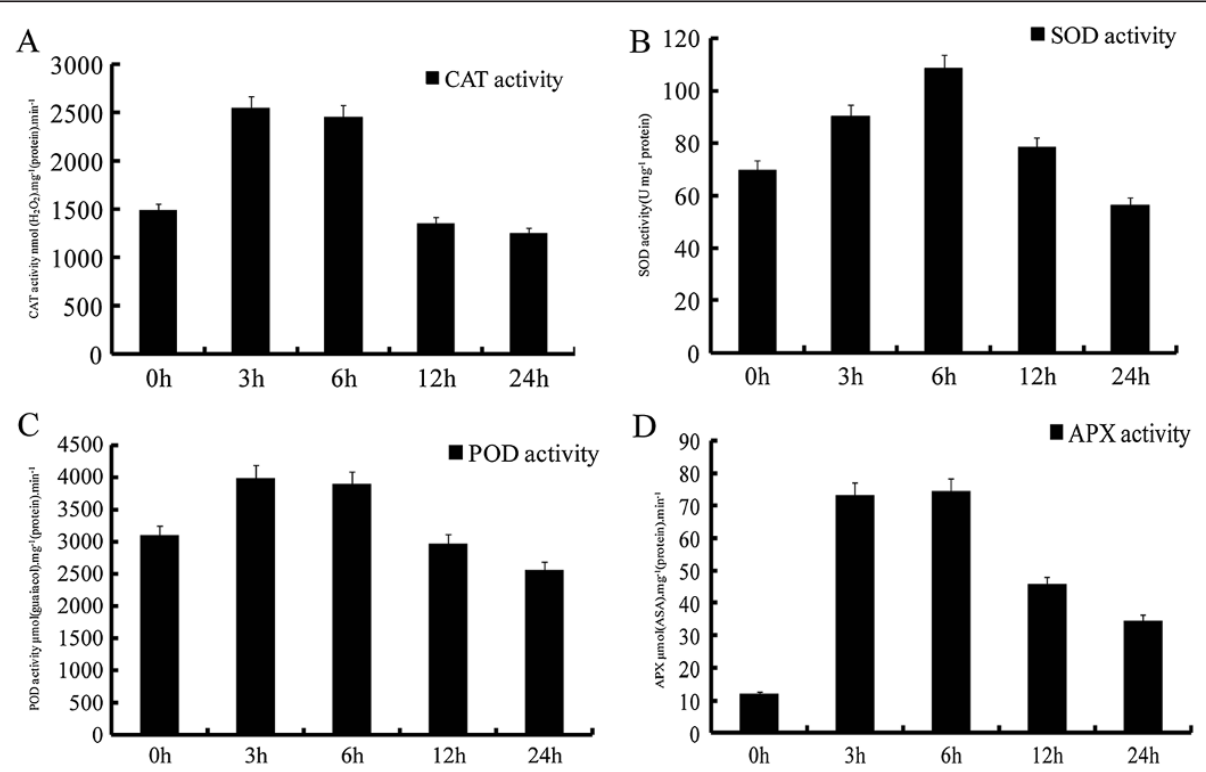

Figure 3 Change of SOD, POD CAT and APX activities response to heat stress. A: SOD activities; B: POD activities; C: CAT activities; D: APX activities. Activities are presented as means \pm standard error, and $n=3$. 


\section{Changes in physiological and biochemical parameters in response to heat stress}

Antioxidant enzymes buffer oxidative stress caused by high temperature. Therefore, we measured the activities of four antioxidant enzymes, SOD, POD CAT and APX (Figure 3). High temperature significantly increased the activities of all antioxidant enzymes at three hours. Subsequently, POD, CAT and APX activities showed no significant change at six hours, but SOD activity sharply increased during exposure to high temperature. After six hours, all four antioxidant enzyme activities decreased from $12 \mathrm{~h}$ to $24 \mathrm{~h}$.

If cellular antioxidants do not sufficiently counter the oxidative stress induced by heat stress, cellular reactive oxygen may cause lipid peroxidation. Therefore, we measured MDA content, a classic marker of lipid peroxidation. The MDA concentration of poplar did not change under heat stress at three hours and six hours of stress treatment but increased and peaked at the $24 \mathrm{~h}$ time point (Figure 4A). To measure endogenous $\mathrm{H}_{2} \mathrm{O}_{2}$ levels, we used an $\mathrm{H}_{2} \mathrm{O}_{2}$-specific fluorescent probe and spectrophotometry. $\mathrm{H}_{2} \mathrm{O}_{2}$ production slightly changed after six hours heat stress and then increased by 3.4-fold, at $12 \mathrm{~h}$ and $24 \mathrm{~h}$ (Figure $4 \mathrm{~B}$ and $\mathrm{C}$ ).

\section{A portrait of the poplar transcriptional response to heat stress}

Measurement of photosynthetic physiological characteristics showed that Pn and iWUE increased significantly after high temperature treatment for six hours, implying there might be a substantial change in gene expression at this time point (Figure $1 \mathrm{~A}$ and $\mathrm{E}$ ). Identifying differentially expressed genes might provide new insights into how poplar maintains photosynthesis under heat stress. Therefore, we used the six hour high temperature treatment group for microarray expression profiling.

Microarray analysis identified 29,896 reliable signatures that were differentially expressed (Fold change $>2$ or $<0.5$; $\mathrm{P}<0.001)$ between treatments and controls; of these, 15,670 were up-regulated and 14,226 were downregulated. Comparative analyses indicated that the highest and lowest expression ratios (heat treated/control) were 2677 and 0.0097 , respectively.

Gene ontology (GO) supplies a unified and structured classification, to specifically describe genes and their products and allows comparison of results from different species. To explore the biological functions of heatresponsive genes, we identified 1,805 genes showing significant differential expression at $P<0.001$ and with expression ratios greater than four-fold as candidate genes for functional enrichment analysis. We then characterized these genes functionally using GO terms (Figure 5); this revealed that eight GO terms for biological process were enriched, including protein folding, mitochondrial transport, protein localization in mitochondrion, protein targeting to mitochondrion, translation, mitochondrion organization, protein import, and protein targeting (Figure 5A). For cellular component, GO analysis revealed that the categories cytoplasm, intracellular part, intracellular, intracellular organelle and organelle were enriched. For categories based on molecular function, the genes were classified into 16 categories. The two most overrepresented
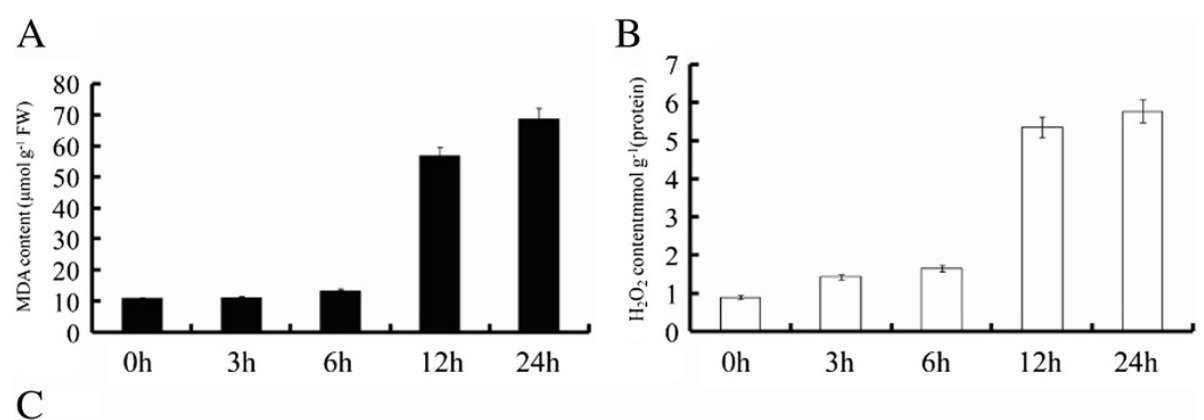

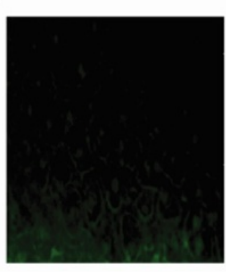

$0 \mathrm{~h}$

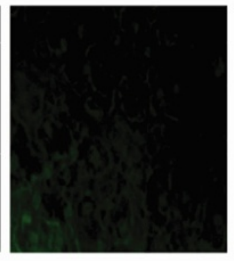

$3 \mathrm{~h}$

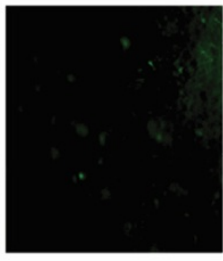

$6 \mathrm{~h}$

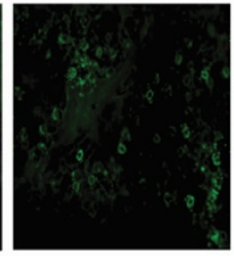

$12 \mathrm{~h}$

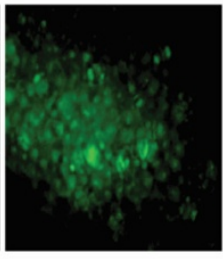

$24 \mathrm{~h}$

Figure 4 Concentration of MDA and $\mathrm{H}_{2} \mathrm{O}_{2}$ in leaves of poplar under high temperature. A: concentration of MDA under heat stress. B: concentration of $\mathrm{H}_{2} \mathrm{O}_{2}$ under heat stress. $\mathbf{C}$ : the changes of $\mathrm{H}_{2} \mathrm{O}_{2}$ under heat stress were detected by $\mathrm{H}_{2} \mathrm{O}_{2}$-specific fluorescent probe H2DCF-DA (green). Oh indicates control group without high temperature treatment. 3-24h indicates different times of exposure to heat stress. Concentrations are presented as means \pm standard error, and $n=3$. 


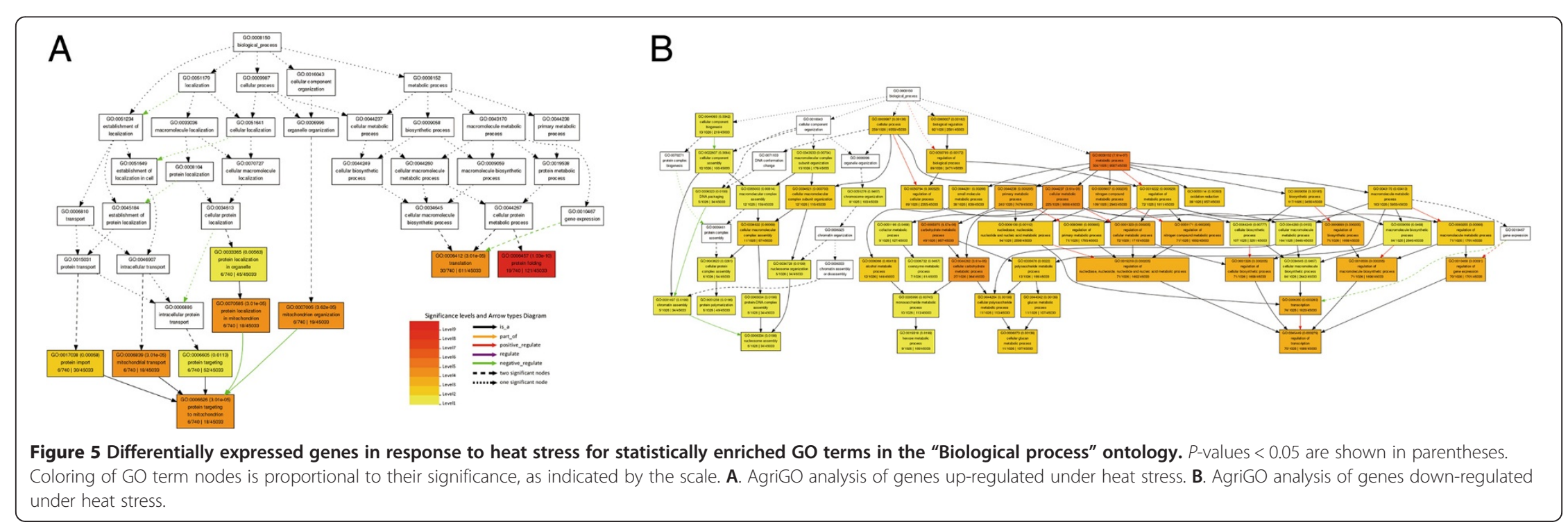


GO terms were structural constituent of ribosome and structural molecule activity (Additional file 3).

For the heat-repressed genes, differentially expressed genes were related to 11 biological processes including metabolic process, primary metabolic process, cellular metabolic process, nitrogen compound metabolic process, biosynthetic process, cellular process, cellular macromolecule metabolic process and macromolecule metabolic process (Figure 5B). For cellular component, the set of GO terms enriched for the heat-repressed genes was similar to those enriched for heat-induced genes. For molecular functions, the down-regulated genes were classified into six categories including catalytic activity, hydrolase activity, cation binding, metal ion binding, ion binding, and zinc ion binding (Additional file 4).

\section{Response of expression of photosynthesis-related genes to heat stress}

Base on the MapMan analysis, fifty-six photosynthesisrelated genes were detected as differentially expressed in the response to heat stress. Among these, twenty-one genes were up-regulated, including eighteen genes involved in light reactions, one gene in the Calvin cycle and two genes for photorespiration (Table 1 and Figure 6). Thirty-six photosynthesis-related genes were repressed under heat stress. Among these, twenty, seven and nine genes are involved in the light reaction, Calvin cycle and photorespiration, respectively.

In the light reaction, fourteen differentially expressed genes affected PSI, including ten up-regulated genes and four down-regulated genes. In contrast, twenty differentially expressed genes were detected for PSII, four upregulated genes and sixteen down-regulated genes. The observation that more genes were down-regulated than up-regulated suggested that PSII might suffer more negative effects from heat stress than PSI (Figure 6). Also, all four genes for the redox chain (PETA, PETM, $P E T B$ and $A T P A)$ were significantly up-regulated after six hours heat stress, suggesting these genes might play important roles in maintaining electron transfer in photosynthesis under heat stress (Table 2).

Eight genes for the Calvin cycle were differentially expressed under heat stress (Table 2). Among these, only RCA (RIBULOSE BISPHOSPHATE CARBOXYLASE/ OXYGENASE ACTIVASE) was significantly up-regulated (six-fold change); the others were down-regulated, ranging

Table 1 Upregulated-genes involved in photosynthesis in the response to heat stress

\begin{tabular}{|c|c|c|c|c|c|c|c|}
\hline Biological process & Location & & Alias & Gene model & Description & $\begin{array}{l}\text { TAIR gene } \\
\text { model }\end{array}$ & $\begin{array}{l}\text { Fold } \\
\text { change }\end{array}$ \\
\hline \multirow[t]{18}{*}{ Light reaction } & \multirow{18}{*}{$\begin{array}{l}\text { Chloroplast } \\
\text { thylakoids }\end{array}$} & \multirow[t]{10}{*}{ PS I } & LHCB2.1 & Potri.014G165100 & chlorophyll a/b-binding protein & AT2G05100 & 2.61 \\
\hline & & & PSBF & Potri.011G095300 & PSIl cytochrome b559 & ATCG00570 & 2.21 \\
\hline & & & PSBK & Potri.013G138100 & PSII PsbK protein & ATcG00070 & 2.02 \\
\hline & & & PSBC & Potri.008G207300 & PSIl protein & ATcG00280 & 6.12 \\
\hline & & & & Potri.002G072400 & thylakoid lumenal $29.8 \mathrm{kDa}$ protein & AT1G77090 & 2.37 \\
\hline & & & PSBL & Potri.002G237300 & PSII L protein & ATcG00560 & 3.97 \\
\hline & & & PSBA & Potri.013G138300 & Photosynthetic reaction centre protein & ATcG00020 & 2.02 \\
\hline & & & PSBK & Potri.013G138100 & PSII PsbK protein & ATcG00080 & 4.84 \\
\hline & & & PSBD & Potri.008G207200 & PSBD | PSII D2 protein & ATcG00270 & 183.90 \\
\hline & & & PSBR & Potri.011G142200 & PSII 10 kDa polypeptide & AT1G79040 & 3.28 \\
\hline & & \multirow[t]{4}{*}{ Redox chain } & PETA & Potri.T058600 & electron carrier activity & ATcG00540 & 9.14 \\
\hline & & & PETM & Potri.004G003000 & cytochrome b6f complex subunit (petM) & AT2G26500 & 9.18 \\
\hline & & & PETB & Potri.013G137300 & Cytochrome b(N-terminal)/b6/petB & ATCG00720 & 24.80 \\
\hline & & & ATPA & Potri.013G138000 & ATP synthase alpha/beta family, & ATcG00120 & 5.01 \\
\hline & & \multirow[t]{4}{*}{ PS ॥ } & ATPC1 & Potri.004G014800 & ATP synthase gamma chain 1 & AT4G04640 & 2.38 \\
\hline & & & OHP2 & Potri.005G196100 & a novel member of the Lhc family & AT1G34000 & 3.54 \\
\hline & & & PSAJ & Potri.003G067400 & Encodes subunit J of PS I & ATcG00630 & 2.74 \\
\hline & & & NDF4 & Potri.001G186800 & Ribosomal protein L33 & AT3G16250 & 2.09 \\
\hline Calvin cycle & $\begin{array}{l}\text { Chloroplast } \\
\text { stroma }\end{array}$ & & $\mathrm{RCA}$ & Potri.008G058500 & $\begin{array}{l}\text { Ribulose bisphosphate carboxylase/ } \\
\text { oxygenase activase }\end{array}$ & AT2G39730 & 6.21 \\
\hline \multirow[t]{2}{*}{ Photo-respiration } & \multirow[t]{2}{*}{ chloroplast } & & $\mathrm{RCA}$ & Potri.008G058500 & $\begin{array}{l}\text { Ribulose bisphosphate carboxylase/ } \\
\text { oxygenase activase }\end{array}$ & AT2G39730 & 6.21 \\
\hline & & & PGLP1 & Potri.008G077400 & 2-phosphoglycolate phosphatase 1 & AT5G36700 & 4.57 \\
\hline
\end{tabular}




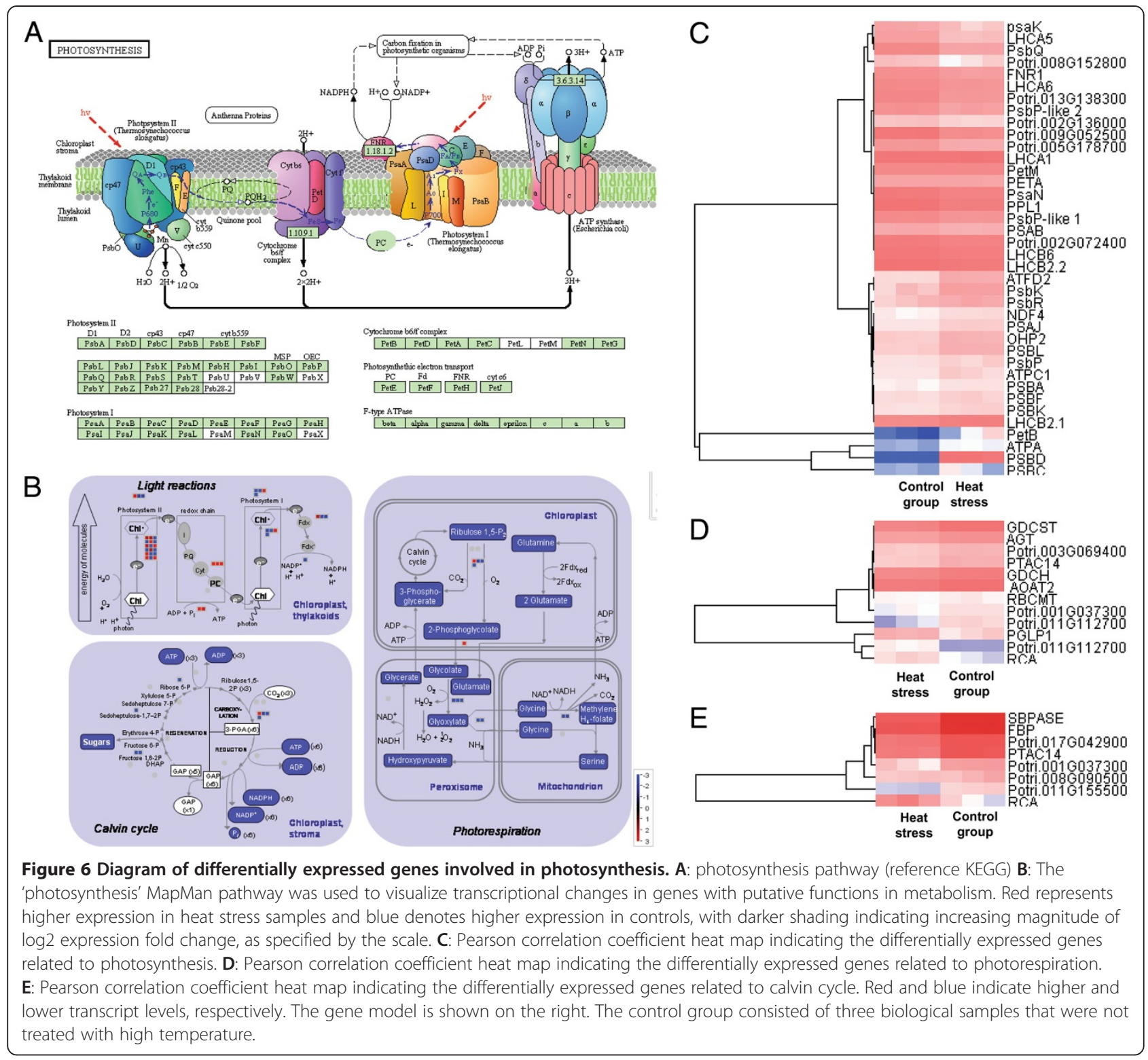

from 0.41- to 0.13-fold change. SBP (SQUAMOSA PROMOTER BINDING PROTEINS) functions at a branch point in the Calvin cycle and its transcripts showed the most decrease, a 0.13-fold change. In photorespiration, among 11 differentially expressed genes, only $R C A$ and PGLP1 (PHOSPHOGLYCOLATE PHOSPHATASE 1) were up-regulated under high temperature treatment (Table 2). The other genes, including AOAT2 and GDCST, associated with transamination and decarboxylation were markedly repressed (Figure 6).

\section{Time-course analysis of electron transfer and $\mathrm{H}_{2} \mathrm{O}_{2}$} production related gene expression under heat stress The photosynthetic analysis revealed an obvious decrease in Pn between the six-hour and twelve-hour heat treatment groups, suggesting that six hours might be a turning point in the photosynthetic response to high temperature treatment. Simultaneously, chlorophyll a fluorescence and physiological analysis indicated that electron transfer rate significantly decreased and large amounts of $\mathrm{H}_{2} \mathrm{O}_{2}$ were generated at twelve hours of high temperature treatment, compared with six hours. Based on these results, we concluded that the inhibition of electron transfer and generation of $\mathrm{H}_{2} \mathrm{O}_{2}$ might cause a reduction of photosynthesis under heat stress. Therefore, based on the transcriptome analysis, we chose four genes (PETA, PETM, PETB and ATPA) associated with electronic transfer rate and four genes (PGLP1, GOX1, GOX2 and GOX3) associated with $\mathrm{H}_{2} \mathrm{O}_{2}$ production as candidate genes for time-course gene expression analysis (Table 3 ). 
Table 2 Downregulated-genes involved in photosynthesis in the response to heat stress

\begin{tabular}{|c|c|c|c|c|c|c|c|}
\hline Biological process & Location & & Alias & Gene model & Description & $\begin{array}{l}\text { TAIR gene } \\
\text { model }\end{array}$ & $\begin{array}{l}\text { Fold } \\
\text { change }\end{array}$ \\
\hline \multirow[t]{20}{*}{ Light reaction } & $\begin{array}{l}\text { Chloroplast } \\
\text { thylakoids }\end{array}$ & PS I & LHCB2.2 & Potri.014G165100 & $\begin{array}{l}\text { similar to chlorophyll a/b-binding } \\
\text { protein - garden pea }\end{array}$ & AT2G05070 & 0.48 \\
\hline & & & LHCB6 & Potri.001G210000 & similar to chlorophyll A-B binding protein; & AT1G15820 & 0.44 \\
\hline & & & PNSL & Potri.010G210000 & PSII reaction center PsbP family protein & AT2G39470 & 0.29 \\
\hline & & & & Potri.008G152800 & similar to PSII $11 \mathrm{kDa}$ protein-related & AT1G05385 & 0.33 \\
\hline & & PS ॥ & & Potri.005G178700 & oxygen-evolving complex-related & AT1G76450 & 0.23 \\
\hline & & & & Potri.009G052500 & similar to PSII $5 \mathrm{kD}$ protein & AT1G51400 & 0.12 \\
\hline & & & & Potri.007G100800 & $\begin{array}{l}\text { a PsbP domain-OEC23 like protein localized } \\
\text { in thylakoid }\end{array}$ & AT2G28605 & 0.07 \\
\hline & & & & Potri.005G206200 & PSII family protein & AT1G03600 & 0.22 \\
\hline & & & PPL1 & Potri.010G210200 & PPL1 (PsbP-like protein 1) & AT3G55330 & 0.23 \\
\hline & & & PSBQ & Potri.001G416400 & $\begin{array}{l}\text { oxygen evolving enhancer } 3 \text { (PsbQ) } \\
\text { family protein; }\end{array}$ & AT3G01440 & 0.11 \\
\hline & & & PSBO1 & Potri.005G130400 & similar to $\mathrm{O}_{2}$ evolving complex $33 \mathrm{kD}$ protein & AT5G66570 & 0.35 \\
\hline & & & LHCA1 & Potri.008G041000 & similar to LHCl type I (CAB) & AT3G54890 & 0.24 \\
\hline & & & LHCA6 & Potri.006G139600 & similar to LHCI type II & AT1G19150 & 0.34 \\
\hline & & & LHCA5 & Potri.014G029700 & similar to chlorophyll A-B binding protein & AT1G45474 & 0.14 \\
\hline & & & PSAN & Potri.007G105900 & PSI subunit Psa N & AT5G64040 & 0.42 \\
\hline & & & PSAB & Potri.017G052700 & PSI psaA/psaB protein & ATcG00340 & 0.28 \\
\hline & & & PSAK & Potri.006G254200 & similar to PSI reaction center subunit Psa K; & AT1G30380 & 0.18 \\
\hline & & & & Potri.002G136000 & ferredoxin-related & AT1G02180 & 0.42 \\
\hline & & & ATFD2 & Potri.004G218400 & $\begin{array}{l}\text { similar to Ferredoxin 2; similar to } \\
\text { chloroplast precursor }\end{array}$ & AT1G60950 & 0.44 \\
\hline & & & FNR1 & Potri.007G057200 & similar to Chain $\mathrm{A}_{\text {; }}$ & AT5G66190 & 0.37 \\
\hline \multirow[t]{7}{*}{ Calvin cycle } & $\begin{array}{l}\text { Chloroplast } \\
\text { stroma }\end{array}$ & & & Potri.011G155500 & $\begin{array}{l}\text { similar to ribose } 5 \text {-phosphate } \\
\text { isomerase-related; }\end{array}$ & AT5G44520 & 0.25 \\
\hline & & & & Potri.008G090500 & similar to Ribulose-1; & AT1G14030 & 0.43 \\
\hline & & & & Potri.001G037300 & $\begin{array}{l}\text { ATPase family associated with various } \\
\text { cellular activities }\end{array}$ & AT1G73110 & 0.38 \\
\hline & & & PTAC14 & Potri.003G155100 & plastid transcriptionally active 14 & AT4G20130 & 0.30 \\
\hline & & & & Potri.017G042900 & Fructose-1-6-bisphosphatase & AT5G64380 & 0.33 \\
\hline & & & FBP & Potri.016G106900 & similar to Redox Signaling In The Chloroplast: & AT3G54050 & 0.20 \\
\hline & & & SBPASE & Potri.010G193300 & similar to Sedoheptulose-1; & AT3G55800 & 0.13 \\
\hline \multirow[t]{9}{*}{ Photo-respiration } & Chloroplast & & RBCMT & Potri.008G090500 & similar to Ribulose-1; & AT1G14030 & 0.43 \\
\hline & & & & Potri.001G037300 & $\begin{array}{l}\text { ATPase family associated with various } \\
\text { cellular activities }\end{array}$ & AT1G73110 & 0.38 \\
\hline & & & PTAC14 & Potri.003G155100 & Rubisco LSMT substrate-binding & AT4G20130 & 0.30 \\
\hline & & & HAOX1 & Potri.003G069400 & similar to (S)-2-hydroxy-acid oxidase; & AT3G14130 & 0.40 \\
\hline & & & GOX3 & Potri.011G112700 & similar to glycolate oxidase & AT4G18360 & 0.08 \\
\hline & & & AOAT2 & Potri.008G187400 & $\begin{array}{l}\text { a protein with glyoxylate aminotransferase } \\
\text { activity }\end{array}$ & AT1G70580 & 0.14 \\
\hline & & & AGT & Potri.001G253300 & similar to aminotransferase 2 & AT2G13360 & 0.07 \\
\hline & & & GDCST & Potri.011G006800 & $\begin{array}{l}\text { similar to T-protein of the glycine } \\
\text { decarboxylase complex }\end{array}$ & AT1G11860 & 0.39 \\
\hline & & & $\mathrm{GDCH}$ & Potri.003G089300 & $\begin{array}{l}\text { similar to glycine cleavage system protein } \\
\mathrm{H} \text { precursor }\end{array}$ & AT1G32470 & 0.45 \\
\hline
\end{tabular}


Table 3 Annotation of 14 candidate genes in the response to heat stress

\begin{tabular}{|c|c|c|c|c|c|c|}
\hline NO & Alias $^{\mathrm{a}}$ & Gene model & Putative function $^{\mathrm{b}}$ & p-value ${ }^{c}$ & q-value ${ }^{d}$ & Fold change \\
\hline 1 & HSFA6B & Potri.005G214800 & Member of Heat Stress Transcription Factor (Hsf) family & $5.78 \mathrm{E}-03$ & $2.96 \mathrm{E}-04$ & 135.79 \\
\hline 2 & DREB7 & Potri.010G183700 & Putative dehydration responsive element binding protein $2 \mathrm{H}$ & $2.59 \mathrm{E}-03$ & $3.11 \mathrm{E}-04$ & 18.26 \\
\hline 3 & DREB8 & Potri.008G073600 & Putative dehydration responsive element binding protein $2 \mathrm{H}$ & $3.07 \mathrm{E}-03$ & $7.25 \mathrm{E}-04$ & 26.42 \\
\hline 4 & PETA & Potri.T058600 & electron carrier activity & $6.73 \mathrm{E}-06$ & $3.11 \mathrm{E}-05$ & 9.14 \\
\hline 5 & PetM & Potri.004G003000 & cytochrome b6f complex subunit (petM) & $3.34 \mathrm{E}-03$ & $1.95 \mathrm{E}-04$ & 9.18 \\
\hline 6 & PetB & Potri.013G137300 & Cytochrome b(N-terminal)/b6/petB & $6.53 \mathrm{E}-08$ & $2.46 \mathrm{E}-04$ & 24.80 \\
\hline 7 & ATPA & Potri.013G138000 & ATP synthase alpha/beta family, & $3.30 \mathrm{E}-05$ & $2.93 \mathrm{E}-04$ & 5.01 \\
\hline 8 & PGLP1 & Potri.008G077400 & 2-phosphoglycolate phosphatase 1 & $6.90 \mathrm{E}-04$ & $3.53 \mathrm{E}-05$ & 4.57 \\
\hline 9 & GOX1 & Potri.001G394400 & similar to glycolate oxidase & $2.53 \mathrm{E}-04$ & 4.15E-05 & 0.052 \\
\hline 10 & GOX2 & Potri.002G027000 & similar to glycolate oxidase & 4.01 E-04 & $2.24 \mathrm{E}-05$ & 0.08 \\
\hline 11 & GOX3 & Potri.011G112700 & similar to glycolate oxidase & $5.63 \mathrm{E}-07$ & 1.66E-05 & 0.087 \\
\hline 12 & Lhcb6 & Potri.003G020400 & Lhcb6 protein, light harvesting complex of PS II & $1.25 \mathrm{E}-03$ & 3.63E-04 & 0.09 \\
\hline 13 & JAZ6 & Potri.003G068900 & JAZ6 transcript levels rise in response to a jasmonate stimulus & $6.53 \mathrm{E}-08$ & $2.46 \mathrm{E}-04$ & 14.15 \\
\hline 14 & Hsp81.4 & Potri.016G003400 & HEAT SHOCK PROTEIN 81.4 & $6.25 \mathrm{E}-03$ & 2.15E-05 & 40.30 \\
\hline
\end{tabular}

Aliases $^{\mathrm{a}}$ and Putative function ${ }^{\mathrm{b}}$ were derived from Joint Genome Institute (JGI: http://www.jgi.doe.gov/).

$\mathrm{p}$-value $\mathrm{c}^{\mathrm{c}}$ candidate genes that showed consistent signal on the arrays were identified using a $p$-value of $<0.001$.

$q$-value ${ }^{d}$ candidate genes were identified using a $q$-value(minimum value of false discover rate) of $<0.001$.

All four genes that function to maintain the electronic transfer rate were persistently up-regulated from three hours to six hours, compared with the control group. Subsequently, all of these genes were repressed dramatically at twelve hours and down-regulated to twenty-four hours. After plants were returned to room temperature for twenty-four hours, PETA and ATPA expression in the three hours and six hours treatment groups recovered to normal levels compared with the control group. In the twelve and twenty-four hour treatment groups, PETA and ATPA expression recovered to $51 \%$ and $74 \%$ of control levels, respectively. By contrast, PETM and PETB expression in the six hours treatment group was higher than in the control group after twenty-four hours of room temperature recovery, suggesting that six hours high temperature treatment could mediate poplar stress adaptation by regulating expression of these two genes (Figure 7).

PGLP1 plays an important role in the generation of glycolate, which is involved in the glycolate metabolism in photorespiration. PGLP1 expression increased over time of exposure to high temperature, suggesting that glycolate accumulated constantly. After twenty-four hours at room temperature, PGLP1 expression completely recovered in the three-hour and six-hour treatment groups. However, PGLP1 expression of the twelve and twenty-four hour treatment groups was higher than the control group after twenty-four hours of recovery, suggesting that glycollic metabolism was induced by heat stress and might be maintained for a long time.

GOX gene family members encode enzymes that catalyze the reaction from glycolate to glyoxylate; this reaction simultaneously produces $\mathrm{H}_{2} \mathrm{O}_{2}$. Three members of the GOX gene family were detected in this study and showed two patterns of expression in response to heat stress. At three- and six-hour time points, all three GOX genes were down-regulated and completely recovered after treatment ended. GOX1, 2 and 3 were significantly induced by heat stress from twelve to twenty-four hours. After recovery, GOX1 expression was higher than the control group, but GOX 2 and 3 were not significantly changed compared with the control group. These results suggest that the three GOX family members show different expression in response to heat stress.

\section{Heat regulation of transcription factors related to photosynthesis}

Transcription factors (TFs) regulate plant abiotic stress responses and mediate stress tolerance [13]. However, only a few TFs are known to regulate the expression of photosynthesis-related genes in response to stress. To understand the expression patterns of TFs that regulate the expression of photosynthesis-related genes under heat stress, we surveyed the expression levels of all TFs using microarray technology. In our study, 165 TF genes were differentially expressed in response to high temperature (Figure 8 and Additional file 5). Among the differentially expressed TF genes, 49 (29.7\%) were upregulated, and 116 (70.3\%) were down-regulated.

bZIP transcription factors have broad functions in plant biotic and abiotic stress responses, light signaling, and ABA signaling [14]. Among the sixteen bZIP transcription factors, five bZIPs were differentially expressed under heat 


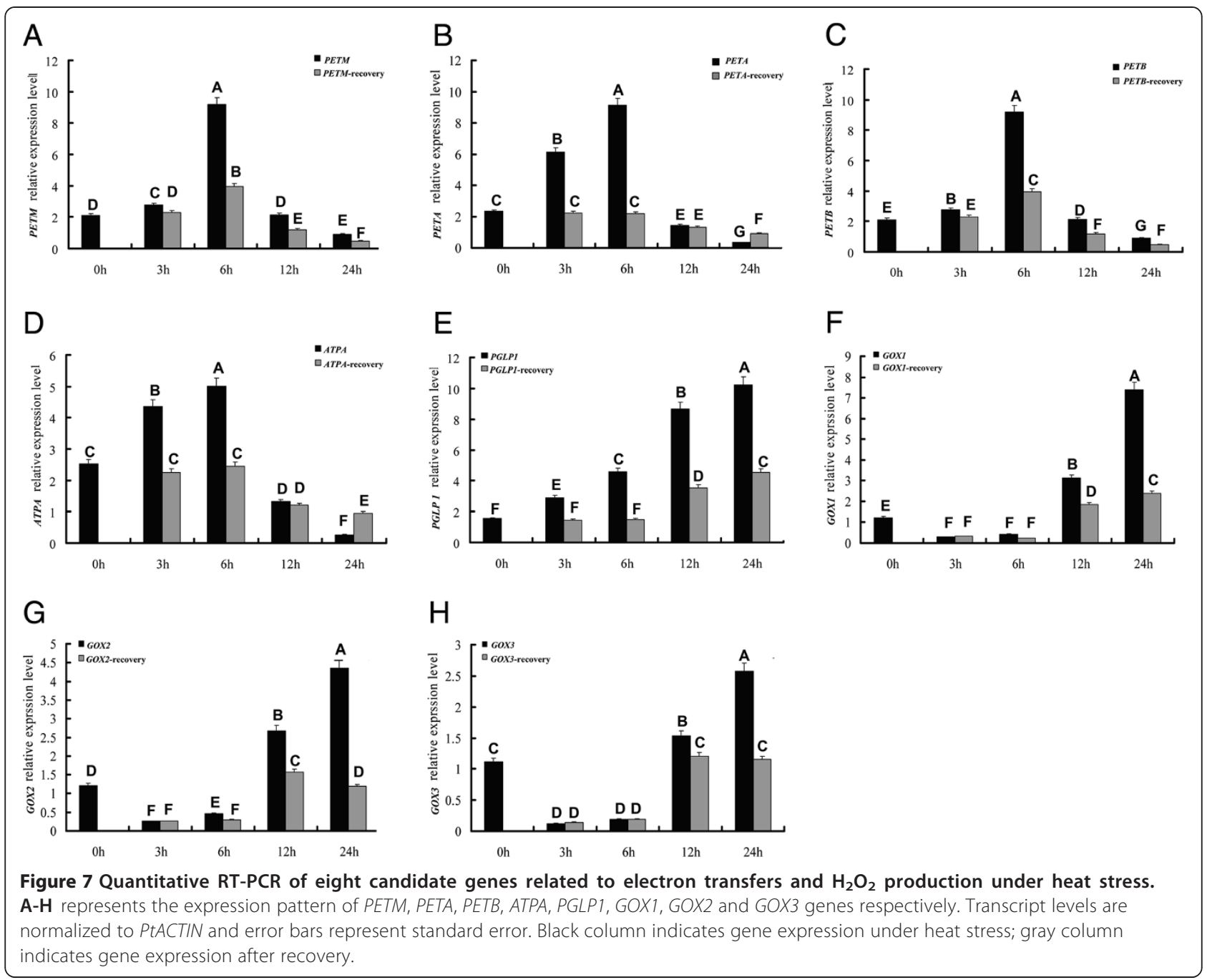

stress (Additional file 5). Among these, bZIP60 and bZIP61 were up-regulated 2.92- and 2.91-fold, respectively.

NAC family transcription factors have been implicated in activation of ERD1 expression [15] and are predominantly induced by abiotic stress in guard cells [16]. Thus, these transcription factors might function in the regulation of photosynthesis under heat stress. Among the 138 NAC family members, 38 were induced under heat stress ranging from 2.06- to 12.23-fold. Expression of NAC 104 and NAC 145 was induced 12.15- and 12.23-fold, respectively (Additional file 5).

$M Y B$ gene family members function in ABA signaling and regulate jasmonic acid-related gene expression, indicating that they affect crosstalk between abiotic and biotic stress responses [17]. In our study, 106 of 178 MYB genes were detected as responsive to heat stress. Of these $M Y B$ genes, 61 were up-regulated, from 2.00- to 39.76-fold. For example, $M Y B 60$, which promotes stomatal opening, increased by 5.55 -fold, but MYB61, which promotes stomatal closure, did not increase (Additional file 5).
$C B F / D R E B 1$ activates the expression of genes for osmoprotectants and antioxidants and its expression was quickly and transiently induced by abiotic stress [13]. Of the 60 members of the DREB gene family, 42 were differentially expressed in response to high temperature treatment, including 19 up-regulated genes and 23 downregulated genes. DREB2, DREB7 and DREB8 were upregulated 13.9-, 18.26- and 26.42-fold respectively.

DOF (DNA binding with One Finger) genes activate expression of photosynthetic genes [36]. In our study, two C2C2-DOF-type TFs (DOF1 and DOF-type) were induced 3.43- and 3.24-fold, respectively.

\section{Expression of heat-shock transcription factors and heat shock protein genes under heat stress}

Heat-shock transcription factors (HSFs) function as key regulators of $A P X 2$ expression in response to oxidative stress caused by excess light [37]. Our microarray data revealed that six $H S F$ genes were expressed under high temperature treatment (Additional file 6). Expression of 


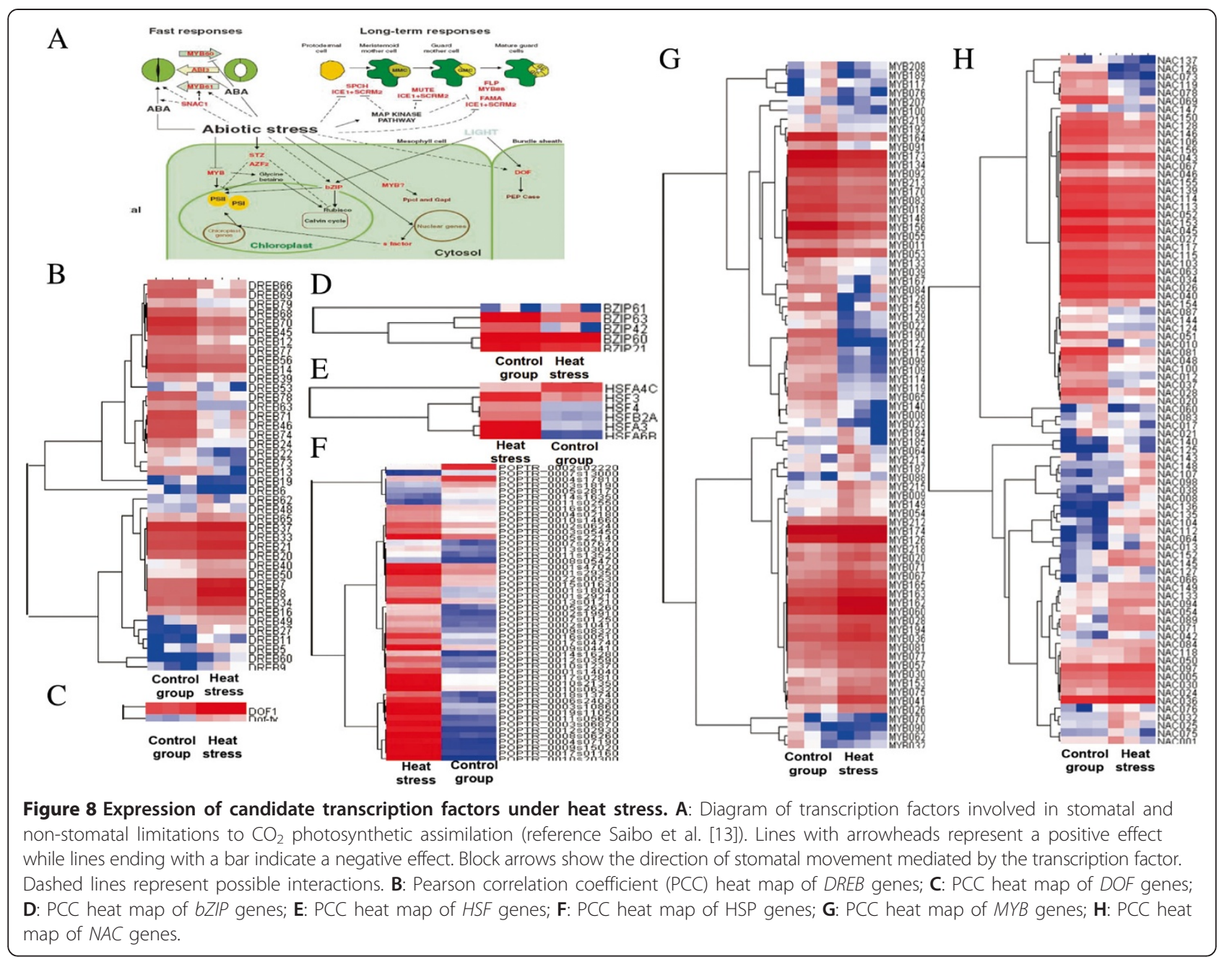

five $H S F$ s expression increased, and only $H S F A 4 C$ was repressed under heat stress. HSFA6B and HSF3 showed the highest transcript abundance among the heat-shock transcription factors, and were induced by 135.8-fold and 48.85 -fold, respectively, compared with the control group.

Heat shock induces heat shock proteins (HSPs), which play a broad role in many cellular processes, including a generalized function in tolerance to multiple environmental stresses apart from heat stress. In this study, 51 $H S P$ genes were differentially expressed in response to heat stress, 44 (86.3\%) up-regulated and 7 (13.7\%) downregulated, with expression ratios ranging from 0.029 to 2677 (Figure 8 and Additional file 6). Two HSP-20 like genes and one HSP90 gene were up-regulated more than 1,000-fold under heat stress (Additional file 6). In addition, seven HSPs were significantly down-regulated under heat stress. The HSPs can be divided into five classes by molecular weight: small HSPs, (15-30 kDa), HSP40, HSP60, HSP70 and HSP80. The number in each class responding to heat stress was different (Additional file 6). Of the genes responding to heat stress, small heat shock proteins, HSP40 and HSP70 make up the majority, approximately $34.4 \%, 33 \%$ and $15.7 \%$ of genes, respectively. Among these genes, CPN60A was significantly up-regulated in response to heat stress and the others were significantly down-regulated.

\section{Verification of microarray data by qRT-PCR}

To validate the microarray data, we used qRT-PCR to measure the expression of selected candidate genes representing a variety of functional categories and expression patterns. We focused primarily on transcripts belonging to categories important for photosynthesis related genes. Therefore, we chose 14 genes affecting carbon fixation, electronic transfer and glycollic metabolism and heat responsive transcription factors (Table 3). Comparison of the two methods suggested that real-time PCR revealed the same tendency in changes in expression as the microarray data, despite some differences in expression level. Hence, the results suggest that the microarray data in this study are reliable. 
Moreover, we sought to confirm whether these genes were generally temperature-responsive. Therefore, we measured the expression of the 14 candidate genes in response to chilling stress (Figure 9). Nine candidate genes did not respond to chilling stress, including HSFA6B, DREB7, DREB8, PGLP1, GOX2, GOX3, JAZ, HSP81.4, and LHCB6. Only PETB showed the same expression tendency under both cold and heat stress. The others showed the opposite tendency of expression under cold and heat stress, including PETA, PETM, ATPA and GOX1.

\section{Discussion}

Physiological, biochemical, and transcriptional mechanisms of plants can be affected by high temperature. As the most fundamental physiological process in plants, photosynthesis provides essential energy for plant growth and metabolism [2]. Damage to photosynthesis components may transiently or permanently reduce the overall photosynthetic capacity of a plant [2]. To understand the effects of high temperature on photosynthesis, we measured physiological, biochemical, chlorophyll fluorescence characters and examined changes in the transcriptome in this study.

\section{Effects of high temperature on photosynthesis}

Photosynthesis has been long recognized as sensitive to environment stresses. Pn decreases if environmental stress affects any component of photosynthesis [2]. Our study revealed that photosynthesis significantly decreased after three hours heat stress and subsequently increased at six hours. The main cause of the reduced Pn may be the changes in Gs and $\mathrm{Ci}$ [38]. If both $\mathrm{Ci}$ and Gs decrease simultaneously, stomatal conductance will mainly limit Pn. By contrast, if $\mathrm{Ci}$ increased, but Gs decreased or did not change, the decrease of Pn might be caused by nonstomatal factors. At three hours high temperature treatment, Gs and Ci decreased simultaneously, suggesting that the decreased Pn is mainly caused by stomatal

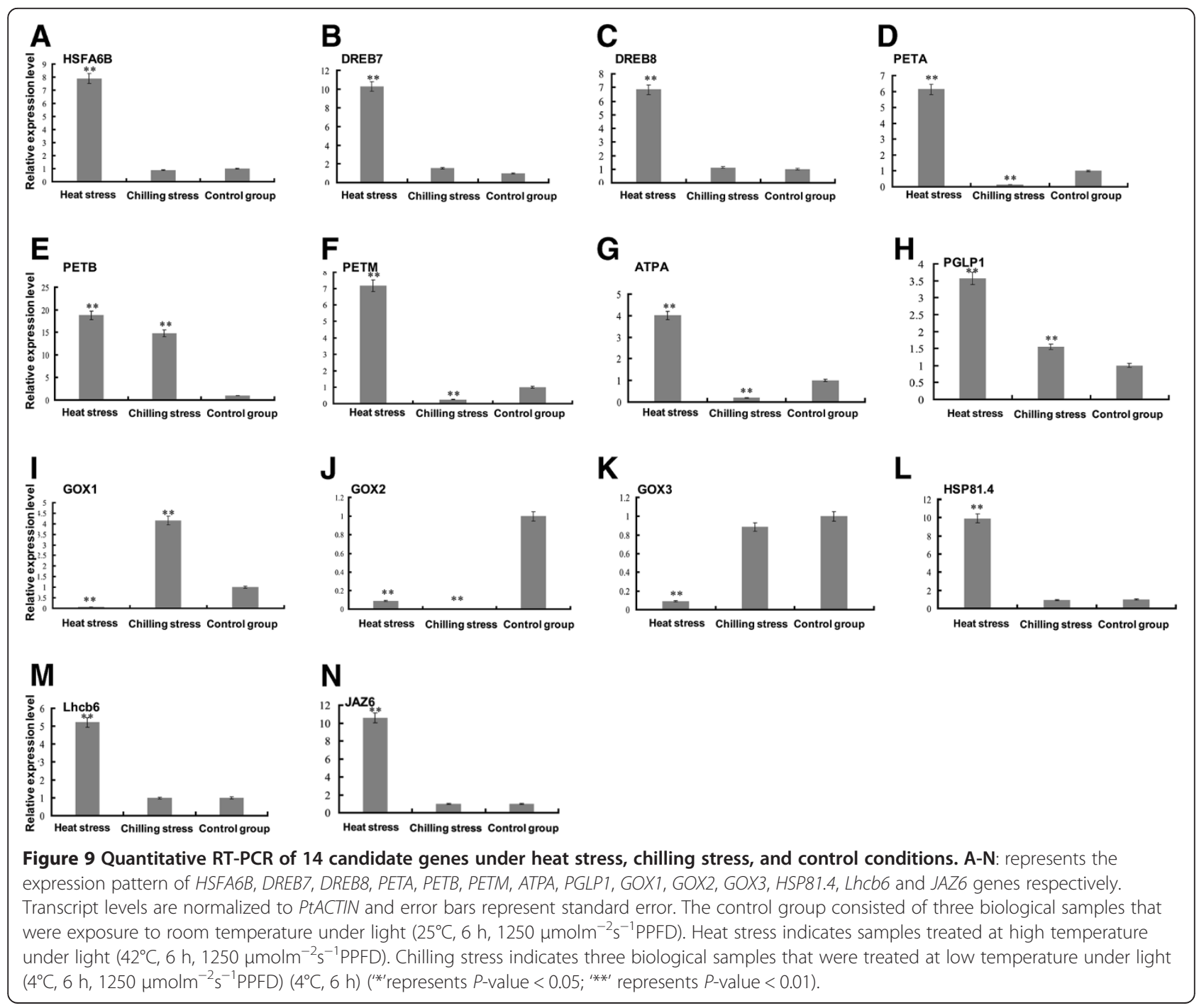


conductance at this time point. Subsequently, a modest increase of Gs and Gi might cause Pn to increase rapidly. After twelve hours of high temperature treatment, Pn, Gs and Gi significantly and simultaneously decreased, suggesting that stomatal conductance again limited Pn in extended heat treatment. Meanwhile, analysis of photosynthesis under heat treatment indicated that photosynthesis completely recovered even six hours treatment. By contrast, after twelve and twenty-four hours of heat treatment, photosynthesis recovered to only $68.8 \%$ and $45.2 \%$ of control group levels, respectively, implying transient or permanent inhibition. Photosynthesis in plants is composed of interconnected biological processes, including $\mathrm{CO}_{2}$ transport and biochemical processes located in the chloroplast thylakoid membranes, stroma, mitochondria and the cytosol of the cell. These biophysical and biochemical processes, and environmental variables determine the net rate of $\mathrm{CO}_{2}$ assimilation [24]. Thus, as suggested by Sharkey et al., 2007, presentation of A-Cc curves and a florescence relaxation analysis should be added in future studies to examine how genetics and environment affect photosynthesis.

As a non-intrusive method, chlorophyll fluorescence analysis can detect the effects of environment stress in plants and give insights into the ability of a plant to tolerant environment stresses [39]. Fo is the fluorescence level when all antenna pigment complexes associated with the photosystem are assumed to be open (dark adapted). An increase of Fo represents the extent to which chloroplasts are affected by an environmental stress. Fv/Fm reflects the photosynthetic capability of the entire PSII and the maximum quantum efficiency of open PSII centers [40]. A significant decrease of Fv/ Fm suggested an increase in energy dissipation as heat and photoinhibition to the photosynthetic apparatus. $q \mathrm{P}$ indicated that a percentage of the PSII reaction centers was closed at any time [41]. We found that Fo increased and $\mathrm{Fv} / \mathrm{Fm}, \mathrm{F}^{\prime} \mathrm{v} / \mathrm{F}^{\prime} \mathrm{m}, q \mathrm{P}$ and ETR significantly decreased along with continuous high temperature $\left(42^{\circ} \mathrm{C}\right)$, suggesting that the photosystem could be inhibited after $12 \mathrm{~h}$ heat stress, together with the limitation of stomatal factors leading Pn, which did not return to normal levels.

\section{Effects of high temperature on activities of antioxidant enzymes}

Temperature stress induced production of reactive oxygen species, which can damage plant cells [42]. To protect the plants from oxidative stress and maintain normal cellular functions, plants have enzymatic scavengers including APX, CAT, POD, SOD, and Glutathione Reductase $[43,44]$. SOD, as a major scavenger of superoxide anion radicals, provides the first defense mechanism of the antioxidant system [45,46], catalysing the dismutation of $\mathrm{O}_{2}{ }^{-}$into $\mathrm{H}_{2} \mathrm{O}_{2}$. Subsequently, CAT, POD and other antioxidant enzymes scavenge $\mathrm{H}_{2} \mathrm{O}_{2}$ [47]. Our results indicated that activities of a set of antioxidant enzymes were induced by high temperature stress at three and six hours, implying that the combined action of SOD, CAT, POD and APX converts the toxic $\mathrm{O}_{2}{ }^{-}$and $\mathrm{H}_{2} \mathrm{O}_{2}$ to water and molecular oxygen $\left(\mathrm{O}_{2}\right)$, thereby protecting the cell from oxidative stress. At twelve and twenty-four hours, all of the activities of antioxidant enzymes were repressed, suggesting that the efficiency of scavenging $\mathrm{O}_{2}{ }^{-}$and $\mathrm{H}_{2} \mathrm{O}_{2}$ might be decreased, thus damaging cellular membranes.

MDA concentrations indicate the extent of lipid peroxidation caused by oxidative stress [48]. In this study, the progressive high temperature stress resulted in MDA concentrations that sharply increased after twelve hours of heat stress, indicating that membrane damage had occurred. Also, $\mathrm{H}_{2} \mathrm{O}_{2}$ increased significantly. Combined with activities of antioxidants enzymes suggesting that efficiency of scavenging $\mathrm{O}_{2}{ }^{-}$and $\mathrm{H}_{2} \mathrm{O}_{2}$ decreased along with decreases in activities of antioxidants enzymes, leading to damage in cellular membrane after twelve hours of heat treatment.

\section{Heat-responsive genes involved in photosynthesis}

Efficient photosynthesis involves photosynthetic pigments and photosystems, the electron transport system, $\mathrm{CO}_{2}$ fixation pathways, and glycollic metabolism. Damage to any of these components may reduce photosynthetic capacity [2]. It has been long believed that the major heat-sensitive component is the PSII center [49]. Consistent with this conclusion, our results revealed that 20 differentially expressed genes were detected for PSII, with only four genes increased and 16 genes decreased. More genes were down-regulated than up-regulated, suggesting that PSII might be suffered more negative effects from heat stress than PSI.

The majority of photosynthetic energy is harnessed via linear electron flow involving light-stimulated electron transfer between two reaction centers, PSI and PSII [50]. Interestingly, in the light reaction, all four genes (PETA, PETB, PETM and ATPA) for the redox chain were upregulated at six hours, implying that electron transport might be induced by high temperature at this timepoint. Sharkey et al. (2005) reported that the cyclic transport of electrons can be induced by moderately high temperature $\left(35^{\circ} \mathrm{C}-45^{\circ} \mathrm{C}\right)$ and thylakoid membranes become leaky at the same time [5]. Tozzi et al. (2013) suggested that significant increases in the rate of cyclic electron transport at high temperatures may counteract thylakoid membrane leakiness and provide protection against irreversible damage. In contrary, Ferreira et al. (2006) indicated that photosynthetic linear electron flow was induced along with a decrease of PSII abundance 
and an increase of PSI in P. euphratica [14]. These suggest that electron transport (cyclic or linear) induced by heat stress in $P$. simonii needs further study.

In photosynthesis, PSBD encodes PSII D2, which produces non-radiative energy dissipation, a highly effective protective mechanism against photodamage. Sane et al. (2002) indicated that the accumulation of PSII D2 protein may promote resistance to high excitation pressure induced by exposure to either low temperature or high light [51]. Our data showed that PSBD was significantly up-regulated at six hours of heat treatment, suggesting that $P S B D$ might be involved in protective mechanisms against photodamage at this time point. Cytochrome b6f mediates the transfer of electrons between the two photosynthetic reaction centers, while protons are transferred from the chloroplast stroma across the thylakoid membrane into the lumen [52]. Electron transport via cytochrome b6f creates the proton gradient that drives the synthesis of ATP in chloroplasts, which is essential for repair of PSII [53]. PETA, PETB, and PETM, encoding cytochrome a, b and $\mathrm{m}(6)$ subunits of the cytochrome b6f complex respectively, were up-regulated significantly under heat stress compared with controls, suggesting that PETB in P. simonii may play an important role in adenosine triphosphate (ATP) production and repair of PSII under heat stress. Meanwhile, ATPA, encoding the ATPase alpha subunit, which catalyzes the conversion of ADP to ATP using the proton motive force, was up-regulated 5.01-fold under heat stress. Gene expression results revealed that the combined action of these four genes promotes the synthesis of ATP under high temperature.

In the Calvin cycle, seven genes involved in carboxylation, reduction and regeneration were significantly repressed, suggesting that these processes were negatively regulated by heat stress (Table 2 and Figure 6). It is fairly well known Rubisco activase enzyme catalyzes the carboxylation of ribulose-1, 5-bisphosphate for fixation of $\mathrm{CO}_{2}$ in photosynthesis and its denaturing/disruption occurs at roughly $35-38^{\circ} \mathrm{C}$ [54]. It is suggesting that the represses of carboxylation processes is likely a cause for the Rubisco decline that causes photosynthesis to plummet at higher temperatures. As suggested by Sharkey and Zhang (2010), Rubisco deactivation may be a protective acclimation strategy for heat tolerance [55]. By contrast, $C P N 60 A$, which is involved in carboxylation, was up-regulated under heat stress. CPN60 plays an important role in protecting plant photosynthesis against heat stress and also affects the recovery of photosynthesis [56]. CPN60A was significantly up-regulated under heat stress, indicating that the mechanisms for protection of photosynthesis were activated in $P$. simonii under heat stress.

As a key role in $\mathrm{CO}_{2}$ fixation, Rubisco is not completely capable of discriminating its substrate $\mathrm{CO}_{2}$ and $\mathrm{O}_{2}$ during oxygenic photosynthesis. Thus, 2-phosphoglycolate (2-PG) is produced by oxygenation of RuBP, a strong inhibitor of enzymes in photosynthetic carbon metabolism [57,58]. 2-PG can be scavenged by photorespiration and converted to 3-phosphoglycerate, which can re-enter the Calvin cycle $[59,60]$. The chloroplast enzyme PGLP1 catalyzes the first reaction of the photorespiratory $\mathrm{C} 2$ cycle that converts 2-phosphoglycolate to glycolate [61]. In our study, PGLP1, encoding 2-phosphoglycolate phosphatase, was persistently up-regulated with heat stress suggesting that the inhibition of photosynthesis was released due to scavenging of 2-PG. This might lead to increases in glycolate concentrations, along with 2-phosphoglycolate metabolism. The photorespiratory enzyme GOX plays an important role in converting glycolate to glyoxylate and in $\mathrm{H}_{2} \mathrm{O}_{2}$ production [62]. Three members of the $G O X$ gene family were differentially expressed under heat stress. At six hours, all three GOX genes were downregulated, suggesting that the conversion of glycolate to glyoxylate was inhibited and $\mathrm{H}_{2} \mathrm{O}_{2}$ was not produced. After twelve hours of high temperature treatment, the abundance of PGLP1 and GOX1-3 transcripts were significantly and consistently increased, suggesting that regulation of these genes, combined with decreases in activities of antioxidant enzymes, might be the main reason for massive production of $\mathrm{H}_{2} \mathrm{O}_{2}$.

After three hours of heat treatment and recovery at room temperature, the expression of all eight candidate genes recovered to control levels, suggesting that plant photosynthesis was not damaged by three hours of heat treatment. Among these genes, PETM and PETB gene expression were higher than controls after recovery from $6 \mathrm{~h}$ heat treatment, implying that moderately high temperature might help ETR, consistent with Sharkey et al. (2005) [5]. After recovery from twelve hours of heat treatment, expression of all ETR-related genes did not recover completely, suggesting that irreversible damage was caused by prolonged heat stress. Differently, expression of PGLP1 and GOX1-3 was higher than the control group under heat stress of more than six hours, implying that the production of $\mathrm{H}_{2} \mathrm{O}_{2}$ might be maintained for a long time. This is consistent with the $\mathrm{H}_{2} \mathrm{O}_{2}$ measurements after recovery from heat stress. $\mathrm{H}_{2} \mathrm{O}_{2}$ is often seen as part of the plant signaling cascade leading to protection from abiotic stresses; therefore PGLP1 and GOX1-3 expression might improve poplar stress adaptation [63].

\section{Heat-responsive transcription factors}

The DREB family is important in regulating plant responses to abiotic stress. DREBs belong to the AP2/ERF family of transcription factors (Yamaguchi-Shinozaki and Shinozaki 1994), which confer stress tolerance in plants and are one of the largest and most diverse families of proteins involved in the regulation of plant responses 
[64]. In Arabidopsis, there are two classes of $D R E B$ genes, DREB1 and DREB2 [65]. DREB2 genes were initially identified as drought and high-salinity response genes [66], and were later shown to be induced in response to heat stress $[67,68]$. However, in this study, only three DREB2 genes were detected and found to be significantly up-regulated under heat stress, suggesting that, in contrast to DREB2, in poplar, DREB1 might not respond to heat stress.

The result that DREBs distinguish cold and dehydration signal transduction pathways was consistent with previous studies. For example, Chen et al. (2010) identified heat shock transcription factor A3 (HsfA3) as a highly up-regulated heat-inducible gene in transgenic plants over-expressing DREB2C [69]. Moreover, HsfA3 expression is directly regulated by $D R E B 2 s$ under heat stress $[69,70]$ and DREB2-overexpressing transgenic plants have increased tolerance to heat stress [71,72]. DREB2C interacts with $\mathrm{ABF} 2$, a bZIP protein regulating $\mathrm{ABA}-$ responsive gene expression, and its overexpression is affected ABA sensitivity [72]. Hwang et al. (2012) found that DREB2C plays an important role in promoting oxidative stress tolerance in Arabidopsis, suggesting that DREB2Cs may function as multi stimuli-response factors that interact with genes and/or proteins during different stress conditions $[73,74]$. In our study, we found that HSFA3 and DREB2C were significantly up-regulated under heat stress, providing indirect evidence for interaction of HSFA3 and DREB2C.

The STRESS-RESPONSIVE NAC1 (SNAC1) gene is predominantly induced by abiotic stress in guard cells [16]. Over-expression of SNAC1 in plants did not produce a negative phenotype, unlike overexpression of $C B F / D R E B 1$ [75]. Overexpression of SNAC1 increased abiotic stress tolerance, reduced transpiration rate and increased ABA sensitivity. Our results indicated that NAC001 was significantly up-regulated after six hours of heat stress with notably increased stomatal closure, suggesting that it plays a key role in regulating stomatal dynamics in poplar under heat stress.

MYB60 and MYB61 are directly involved in stomatal dynamics in Arabidopsis and play opposite roles in stomatal closure: $M Y B 60$ promotes stomatal opening, and $M Y B 61$ promotes stomatal closure [76,77]. In rice, the over-expression of SNAC1 up-regulates MYB61 [16]. In this study, $M Y B 61$ was not expressed, suggesting that the regulatory relationship of $N A C 1$ and $M Y B 61$ is still unclear. $M Y B 60$ expression was significantly up-regulated, suggesting that it might play a key role in stomatal conductance from three to six hours of heat stress.

$D O F 1$, as an activator of transcription, can regulate photosynthesis-related genes in accumulation of grain proteins and affect yield through regulation of nitrogen metabolism [78,79]). Over-expression of DOF1 enhances expression of genes associated with carbon skeleton production [80]. In our study, DOF1 was significantly upregulated under heat stress, suggesting carbon fixation might not be repressed under six hours of heat stress.

\section{Conclusion}

This study provides a systematic physiological and global expression profile of the response of poplar photosynthetic to heat stress. Analysis of photosynthesis under heat treatment indicated that stomatal conductance is the main cause for the decrease in $\mathrm{Gs}$ and $\mathrm{Ci}$ at three hours, and continuing after twelve hours, of high temperature treatment. Over twelve hours high temperature treatment might cause permanent inhibition of photosynthesis. Chlorophyll fluorescence analysis showed that photosystems could be inhibited after twelve hours heat stress, together with the limitation of stomatal factors altering Pn, which did not completely return to normal levels. Combined photosynthetic physiology and gene expression analyses indicated that ETR, in the light reaction, was not significantly changed, but expression of four genes (PETA, PETB, PETM and ATPA) for the redox chain was up-regulated at six hours heat stress, implying that cyclic electron transport might be induced by high temperature at this time point. In the Calvin cycle, three genes involved in carboxylation were significantly repressed, suggesting that repression of carboxylation processes is the likely cause for the decline in Rubisco activity, which causes photosynthesis to plummet at higher temperatures.

Our physiological results showed that twelve hours heat stress is a threshold for the combined action of antioxidant enzymes that convert the toxic $\mathrm{O}_{2}{ }^{-}$and $\mathrm{H}_{2} \mathrm{O}_{2}$ to water and $\mathrm{O}_{2}$, thereby protecting the cell from oxidative stress. Meanwhile, the abundance of PGLP1 and GOX1-3 transcripts significantly and consistently increased, along with decreases in activities of antioxidant enzymes, which might be the main reason for massive production of $\mathrm{H}_{2} \mathrm{O}_{2}$. Also, expression of PGLP1 and GOX1-3 was higher than the control group under heat stress of more than six hours, implying that the production of $\mathrm{H}_{2} \mathrm{O}_{2}$ might be maintained for a long time. $\mathrm{H}_{2} \mathrm{O}_{2}$ has important functions in plant signaling cascades leading to protection from abiotic stresses; therefore PGLP1 and GOX1-3 might be important candidate genes for improving poplar stress adaptation in future research.

The genome-wide gene expression analysis conducted in this study detected a set of heat-responsive transcription factors, which included HSFA3, DREB2C, NAC1, $M Y B 60$ and DOF1. These genes play important roles in regulating stomatal dynamics and heat stress responses in poplar under high temperature treatment. Thus, the photosynthetic physiology and gene expression analyses of this study have expanded our understanding of plant thermostability and will help identify candidate genes that regulate the heat stress response of poplar. 


\section{Additional files}

\section{Additional file 1: Real-time PCR primer sequences. \\ Additional file 2: Poplar ACTINII-like gene (Accession number: $\mathrm{EF}$ 145577) has stable expression under high temperature treatment and was used as the internal control. \\ Additional file 3: GO terms of genes up-regulated under heat stress. Additional file 4: GO terms of genes down-regulated under heat stress. \\ Additional file 5: Candidate transcription factors. \\ Additional file 6: Differentially expressed HSF and HSP genes.}

\section{Abbreviations}

ATP: Adenosine triphosphate; ATPA: A-subunit of the coupling-factor-1 (CF1) ATP synthase; AOAT2: Alanine-2-oxoglutarate aminotransferase 2; bZIP: Basic leucine zipper; CAT: Catalase; CBF/DREB1: C repeat binding factor/drought response element binding 1; $\mathrm{Ci}$ : Intercellular $\mathrm{CO}_{2}$ concentration; CPN60A: Chaperonin-60ALPHA; DOF: DNA binding with one finger; ETR: Electron transport rate; ERD1: Early responsive to dehydration stress 1; Fo: minimum fluorescence; Fm: maximum fluorescence; Fv: Variable fluorescence; F'o: The minimum fluorescence; F'v: Variable fluorescence; F'm: Maximum fluorescence; Fs: Steady state parameter; GDCST: T-Protein of the glycine; GOX1: Glycolate oxidase 1; GOX2: Glycolate oxidase 2; GOX3: Glycolate oxidase 3; Gs: Stomatal conductance; $\mathrm{H} 2 \mathrm{DCF}-\mathrm{DA}$ : $\mathrm{H}_{2} \mathrm{O}_{2}$-specific fluorescent probe 2',7'-Dichlorodihydrofluorescein diacetate; HSFS: Heat-shock transcription factors; HSFA3: Heat shock transcription factor A3; iWUE: Intrinsic water use efficiency; MDA: Malondialdehyde; NAC: NAM, ATAF1/2, CUC2; PETA: Photosynthetic electron transport A; PETM: Photosynthetic electron transport $M$; PETB: Photosynthetic electron transport B; PGLP1: Phosphoglycolate phosphatase 1; Pn: net photosynthetic rate; POD: peroxidase; qP: Photochemical quenching; qPCR: Quantitative real-time polymerase chain reaction; RCA: Ribulose bisphosphate carboxylase/oxygenase activase; SBP: Squamosa promoter binding proteins; SNAC1: Stressresponsive NAC1; SOD: Superoxide dismutase; Tr: transpiration rate; TFs: Transcription factors.

\section{Competing interests}

The authors declared that they have no competing interests.

\section{Authors' contributions}

Conceived and designed the experiments: DZ. Performed the experiments: YS, QC, QC, XS, and DZ. Analyzed the data: YS, QC, XS, DC, and DZ. Contributed reagents/materials/analysis tools: DZ. Wrote the paper: YS, QC, and, DZ. All authors read and approved the final manuscript.

\section{Acknowledgments}

This work was supported by grants from: the Forestry Public Benefic Research Program (No. 201204306), and the 111 Project (No. B13007), and Projects of the National Natural Science Foundation of China (No. 30600479, 30872042),

Program for New Century Excellent Talents in University (No. NCET-07-0084).

\section{Accession numbers}

The gene expression data reported here are available from NCBI with the GEO accession number GSE41557.

Received: 9 December 2013 Accepted: 8 April 2014 Published: 28 April 2014

\section{References}

1. Pan J, Lin S, Woodbury NW: Bacteriochlorophyll excitedstate quenching pathways in bacterial reaction centers with the primary donor oxidized. J Phys Chem B 2012, 116:2014-2022.

2. Ashraf $M$, Harris PJC: Photosynthesis under stressful environments: An overview. Photosynthetica 2013, 51:163-190.

3. Berry J, Bjorkman O: Photosynthetic response and adaptation to temperature in higher-plants. Annu Rev Plant Physiol 1980, 31:491-543.
4. Ferreira S, Hjernø K, Larsen M, Wingsle G, Larsen P, Fey S, Roepstorff P, Salomé Pais M: Proteome profiling of Populus euphratica Oliv. upon heat stress. Ann Bot 2006, 98:361-77.

5. Sharkey TD: Effects of moderate heat stress on photosynthesis: importance of thylakoid reactions, Rubisco deactivation, reactive oxygen species, and thermotolerance provided by isoprene. Plant Cell Environ 2005, 28:269-277.

6. Wang WX, Vinocur B, Shoseyov O: Altman A Biotechnology of plant osmotic stress tolerance: physiological and molecular considerations. Acta Hort 2001, 560:285-292.

7. Yan K, Chen P, Shao H, Zhang L, Xu G: Effects of Short-Term High Temperature on Photosynthesis and Photosystem II Performance in Sorghum. J Agronomy \& Crop Science 2011, 197:400-408.

8. IPCC (Intergovernmental Panel on Climate Change: In Climate Change. Edited by The Core Writing Team,R.K. Pachauri \& A. Reisinger. Geneva, Switzerland: IPCC; 2007:43-54.

9. Eitzinger J, Orlandini S, Stefanski R, Naylor REL: Climate change and agriculture: introductory editorial. J Agric Sci 2010, 148:499-500.

10. Li PM, Cheng LL, Gao HY, Jiang CD, Peng T: Heterogeneous behavior of PS II in soybean (Glycine max) leaves with identical PS II photochemistry efficiency under different high temperature treatments. J Plant Physiol 2009, 166:1607-1615.

11. Mathur S, Allakhverdiev SI, Jajoo A: Analysis of high temperature stress on the dynamics of antenna size and reducing side heterogeneity of photosystem II in wheat leaves (Triticum aestivum). Biochim Biophys Acta 1807, 2011:22-29.

12. Ma T, Wang JY, Zhou GK: Genomic insights into salt adaptation in a desert poplar. Nat Commun 2013, 4:2797.

13. Saibo NJM, Lourenc T, Oliveira MM: Transcription factors and regulation of photosynthetic and related metabolism under environmental stresses. Ann Bot 2009, 103:609-623.

14. Jakoby M, Weisshaar B, Dröge-Laser W, Vicente-Carbajosa J, Tiedemann J, Kroj T, Parcy F: bZIP transcription factors in Arabidopsis. Trends Plant Sci 2002, 7:106-11.

15. Tran LS, Nakashima K, Sakuma Y, Osakabe Y, Qin F, Simpson SD, Maruyama K, Fujita Y, Shinozaki K, Yamaguchi-Shinozaki K: Co-expression of the stress-inducible zinc finger homeodomain ZFHD1 and NAC transcription factors enhances expression of the ERD1 gene in Arabidopsis. Plant J 2007, 49:46-63.

16. $\mathrm{Hu} H \mathrm{HH}$, Dai MQ, Yao JL, Xiao BZ, Li XH, Zhang QF, Xiong LZ: Overexpressing a NAM, ATAF, and CUC (NAC) transcription factor enhances drought resistance and salt tolerance in rice. Proc Natl Acad Sci 2006, 103:12987-12992.

17. Abe H, Urao T, Ito T, Seki M, Shinozaki K, Yamaguchi-Shinozaki K: Arabidopsis AtMYC2 (bHLH) and AtMYB2 (MYB) function as transcriptionalactivators in abscisic acid signaling. Plant Cell 2003, 15:63-78.

18. Brunner AM, Busov VB, Strauss SH: Poplar genome sequence: functional genomics in an ecologically dominant plant species. Trends in Plant Sci 2004, 9:49-56.

19. Jansson S, Douglas CJ: Populus: A model system for plant biology. Annu Rev Plant Bio 2007, 58:425-458.

20. Wang L, Wang BL, Wei ZZ, Du QZ, Zhang DQ, Li BL: Development of 35 microsatellite markers from heat stress transcription factors in Populus simonii (Salicaceae). Am J Bot 2012, 99:357-361.

21. Song YP, Chen QQ, Ci D, Zhang DQ: Transcriptome profiling reveals differential transcript abundance in response to chilling stress in Populus simonii. Plant Cell Rep 2013, 32:1407-25.

22. Chen $J$ H, Song YP, Zhang H, Zhang DQ: Genome-wide analysis of gene expression in response to drought stress in Populus simonii. Plant Mol Biol Reporter 2013, 31:946-962.

23. Salvucci ME, Crafts-Brandner SJ: Inhibition of photosynthesis by heat stress: the activation state of Rubisco as a limiting factor for photosynthesis. Physiol Plantarum 2004, 120:179-186.

24. Sharkey TD, Bernacchi CJ, Farquhar GD, Singsaas EL: Fitting photosynthetic carbon dioxide response curves for C3 leaves. Plant Cell Environ 2007, 30:1035-1040.

25. Chen FG, Chen LG, Zhao HX, Korpelainen H, Li CY: Sex-specific responses and tolerances of Populus cathayana to salinity. Physiol Plant 2010, 140:163-173.

26. Giannopolitis CN, Ries SK: Superoxide dismutases I Occurrence in higher plants. Plant Physiol 1977, 59:309-314. 
27. Bestwick CS, Brown IR, Mansfield JW: Localized changes in peroxidaseactivity accompanies hydrogen peroxide generation during the development of a nonhosthypersensitive reaction in lettuce. Plant Physiol 1998, 118:1067-1078.

28. Carrillo MC, Kanai S, Sato Y, Kitani K: Age-related changes in antioxidant enzyme activities is region and organ, as well as sex, selective in the rat. Mech Ageing Dev 1992, 65:187-198.

29. Dhindsa RS, Plumb-Dhindsa P, Thorpe TA: Leaf senescence: correlated with increased levels of membrane permeability and lipid peroxidation, and decreases levels of superoxidedismutase and catalase. J Exp Bot 1981, 32:93-101.

30. Song YP, Ma KF, Ci D, Zhan ZY, Zhang DQ: Biochemical, physiological and gene expression analysis reveals sex-specific differences in Populus tomentosa floral development. Physiol Plant 2013, 150:18-31.

31. Nakano $Y$, Asada K: Hydrogen peroxide is scavenged by ascorbate-specific peroxidase in spinach chloroplasts. Plant Cell Physiol 1981, 22:867-880.

32. Dat JF, Lopez-Delgado $\mathrm{H}$, Foyer $\mathrm{CH}$, Scott IM: Parallel changes in $\mathrm{H}_{2} \mathrm{O}_{2}$ and catalase during thermotolerance induced by salicylic acid or heat acclimation in mustard seedlings. Plant Physiol 1998, 116:1351-1357.

33. Tozzi E, Easlon HM, Richards JH: Interactive effects of water, light and heat stress on photosynthesis in Fremont cottonwood. Plant Cell Environ 2013, 36:1423-1434.

34. Zhang DQ, Du QZ, Xu BH, Zhang ZY, Li BL: The actin multigene family in Populus: organization, expression and phylogenetic analysis. Mol Genet Genomics 2010, 284:105-119.

35. Morales M, Abadía A, Abadía J: Photoinhibition and Photoprotection under Nutrient Deficiencies, Drought and Salinity. In the Photoprotection, Photoinhibition, Gene Regulation, and Environment. Edited by Demmig-Adams B, Adams WW, Mattoo AK. Dordrech: Springer-Verlag; 2008:65-85.

36. Yanagisawa S, Sheen J: Involvement of maize DOF zinc finger proteins in tissue-specific and light-regulated gene expression. Plant Cell 1998, 10:75-89.

37. Jung HS, Crisp PA, Estavillo GM, Cole B, Hong F, Mockler TC, Pogson BJ, Chory J: Subset of heat-shock transcription factors required for the early response of Arabidopsis to excess light. Proc Natl Acad Sci 2013, 110:14474-14479.

38. Farquhar GD, Sharkey TD: Stomatal conductance and photosynthesis. Annu Rev Plant Physiol 1982, 33:317-345.

39. Maxwell K, Johnson GN: Chlorophyll fluorescence-a practical guide. J Exp Bot 2000, 51:659-668.

40. Lu CM, Zhang JH: Heat-induced multiple effects on PS II in wheat plants. J Plant Physiol 2000, 156:259-265.

41. Efeoğlu B, Ekmekçi Y, Çiçek N: Physiological responses of three maize cultivars to drought stress and recovery. J S Afr Bot 2009, 75:34-42.

42. Chaitanya K, Sundar D, Masilamani S, Ramachandra RA: Variation in heat stress-induced antioxidant enzyme activities among three mulberry cultivars. Plant Growth Regul 2002, 36:175-180.

43. Bettaieb T, Mahmoud M, de Galarreta JI R, Du Jardin P: Relation betweenthe low temperature stress and catalase activity in gladiolus somaclones (Gladiolus grandiflorus Hort.). Sci Hortic-Amsterdam 2007, 113:49-51.

44. Garbero M, Pedranzani H, Zirulnik F, Molina A, Pérez-Chaca MV, Vigliocco A, Abdala G: Short-term cold stress in two cultivars of Digitaria eriantha: effects on stress-related hormones and antioxidant defense system. Acta Physiol Plant 2011, 33:497-507.

45. Asada K: The water-water cycle in chloroplasts: scavenging of active oxygens and dissipation of excess photons. Annu Rev Plant Physiol Plant Mol Biol 1999, 50:601-639.

46. Zhu JJ, Zhang JL, Liu HC, Cao KF: Photosynthesis, non-photochemical pathways and activities of antioxidant enzymes in a resilient evergreen oak under different climatic conditions from a valley-savanna in Southwest China. Physiol Plant 2009, 135:62-72.

47. Liu CC, Liu YG, Guo K, Fan D, Li G, Zheng YR, Yu LF, Yang R: Effect of drought on pigments, osmotic adjustment and antioxidant enzymes in six woody plant species in karst habitats of southwestern China. Environ Exp Bot 2011, 71:174-183.

48. Smirnoff $\mathrm{N}$ : The role of active oxygen in the response of plant to water deficit and desiccation. New Phytol 1993, 125:27-58.

49. Schrader SM, Wise RR, Wacholtz WF, Ort DR, Sharkey TD: Thylakoid membrane responses to moderately high leaf temperature in Pima cotton. Plant Cell Environ 2004, 27:725-735.
50. Livingston AK, Cruz JA, Kohzuma K, Dhingr A, Kramera DM: An Arabidopsis mutant with high cyclic electron flow around photosystem I (hcef) involving the NADPH dehydrogenase complex. Plant Cell 2010, 22:221-233.

51. Sane PV, Ivanov AG, Sveshnikov D, Huner NPA, Alexander G, Öquist G: A Transient exchange of the photosystem II reaction center protein D1:1 with D1:2 during low temperature stress of Synechococcus sp. PCC 7942 in the light lowers the redox potential of QB*. J Bio Chem 2002, 36:32739-32745.

52. Genji K, Huamin Z, Janet L, William A, Cramer S: Structure of the Cytochrome b6f complex of oxygenic photosynthesis: Tuning the cavity. Science 2003, 302:1009-1014.

53. Martin RE, Thomas DJ, Tucker DE, Herbert SK: The effects of photooxidative stress on photosystem I measured in vivo in Chiamydomonas. Plant Cell Environ 1997, 20:45-46

54. Feller $U$, Anders I, Mae T: Rubiscolytics: fate of Rubisco after its enzymatic function in a cell is terminated. J Exp Bot 2008, 59:1615-24.

55. Sharkey TD, Zhang R: High temperature effects on electron and proton circuits of photosynthesis. J Integr Plant Biol 2010, 52:712-722.

56. Rajaram H, Apte SK: Nitrogen status and heat-stress-dependent differential expression of the cpn60 chaperonin gene influences thermotolerance in the cyanobacterium Anabaena. Microbiol 2008, 154:317-325.

57. Anderson LE: Chloroplast and cytoplasmic enzymes II Pea leaf triose phosphate isomerases. Biochim Biophys Acta 1971, 235:237-244.

58. Kelly GJ, Latzko E: Inhibition of spinach-leaf phosphofructokinase by phosphoglycollate. FEBS Letters 1976, 68:55-58.

59. Maurino VG, Peterhansel C: Photorespiration: current status and approaches for metabolic engineering. Curr Opin Plant Biol 2010, 13:249-256.

60. Peterhansel C, Braun HP, Espie GS, Fernie AR, Hanson DT, Keech O, Maurino VG, Mielewczik GM, Sage RF: Engineering photorespiration: current state and future possibilities. Plant Biology 2013, 15:754-758.

61. Schwarte $\mathrm{S}$, Bauwe H: Identification of the Photorespiratory 2Phosphoglycolate Phosphatase, PGLP1, in Arabidopsis. Plant Physiol 2007, 144:1580-1586.

62. Rojas CM, Mysore KS: Glycolate oxidase is an alternative source for $\mathrm{H}_{2} \mathrm{O}_{2}$ production during plant defense responses and functions independently from NADPH oxidase. Plant Signaling \& Behavior 2012, 7:752-755.

63. Foyer $\mathrm{CH}$, Lopez-Delgado H, Dat JF, Scott IM: Hydrogen peroxide- and glutathione-associated mechanisms of acclimatory stress tolerance and signaling. Physiol Plant 1997, 100:241-254.

64. Agarwal M, Hao Y, Kapoor A, Dong CH, Fujii H, Zheng X, Zhu JK: A R2R3 type MYB transcription factor is involved in the cold regulation of CBF genes and in acquired freezing tolerance. J Biol Chem 2006, 281:37636-37645.

65. Sakuma Y, Liu Q, Dubouzet JG, Abe H, Shinozaki K, Yamaguchi-Shinozaki K: DNA-binding specificity of the ERF/AP2 domain of Arabidopsis DREBs, transcription factors involved in dehydration- and cold-inducible gene expression. Biochem Biophys Res Commun 2002, 290:998-1009.

66. Liu Q, Kasuga M, Sakuma Y, Abe H, Miura S, Yamaguchi-Shinozaki K, Shinozaki K: Two transcription factors, DREB1 and DREB2, with an EREBP/AP2 DNA binding domain separate two cellular signal transduction pathways in drought- and low-temperature-responsive gene expression, respectively, in Arabidopsis. Plant Cell 1998, 10:1391-1406.

67. Lim CJ, Hwang JE, Chen H, Hong JK, Yang KA, Choi MS, Lee KO, Chung WS, Lee SY, Lim CO: Over-expression of the Arabidopsis DRE/CRT-binding transcription factor DREB2C enhances thermotolerance. Biochem Biophys Res Commun 2007, 362:431-436.

68. Sakuma Y, Maruyama K, Osakabe Y, Qin F, Seki M, Shinozaki K, YamaguchiShinozaki K: Functional analysis of an Arabidopsis transcription factor, DREB2A, involved in drought-responsive gene expression. Plant Cell 2006, 18:1292-1309.

69. Chen H, Hwang JE, Lim CJ, Kim DY, Lee SY, Lim CO: Arabidopsis DREB2C functions as a transcriptional activator of $\mathrm{HsfA} 3$ during the heat stress response. Biochem Biophys Res Commun 2010, 401:238-244.

70. Schramm F, Larkindale J, Kiehlmann E, Ganguli A, Englich G, Vierling E, von Koskull-Döring P: A cascade of transcription factor DREB2A and heat stress transcription factor $\mathrm{HsfA} 3$ regulates the heat stress response of Arabidopsis. Plant J 2008, 53:264-274. 
71. Almoguera C, Prieto-Dapena P, Díaz-Martín J, Espinosa JM, Carranco R, Jordano J: The HaDREB2 transcription factor enhances basal thermotolerance and longevity of seeds through functional interaction with HaHSFA9. BMC Plant Biol 2009, 9:75.

72. Lee SJ, Kang JY, Park HJ, Kim MD, Bae MS, Choi HI, Kim SY: DREB2C interacts with $A B F 2$, a bZIP protein regulating abscisic acid-responsive gene expression, and its overexpression affects abscisic acid sensitivity. Plant Physiol 2010, 153:716-727.

73. Hwang JE, Lim CJ, Chen H, Je J, Song C, Lim CO: Overexpression of Arabidopsis dehydration-responsive element-binding protein $2 \mathrm{C}$ confers tolerance to oxidative stress. Mol Cells 2012, 33:135-140.

74. Lee K, Han KS, Kwon YS, Lee JH, Kim SH, Chung WS, Kim Y, Chun SS, Kim HK, Bae DW: Identification of potential DREB2C targets in Arabidopsis thaliana plants overexpressing DREB2C using proteomic analysis. Mol Cells 2009, 28:383-388.

75. Ito Y, Katsura K, Maruyama K, Taji T, Kobayashi M, Seki M, Shinozaki K, Yamaguchi-Shinozaki K: Functional analysis of rice DREB1/CBF-type transcription factors involved in cold-responsive gene expression in transgenic rice. Plant Cell Physiol 2006, 47:141-153.

76. Cominelli E, Galbiati M, Vavasseur A, Conti L, Sala T, Vuylsteke M, Leonhardt N, Dellaporta SL, Tonelli C: A guard-cell-specific MYB transcription factor regulates stomatal movements and plant drought tolerance. Curr Biol 2005, 15:1196-1200.

77. Liang YK, Dubos C, Dodd IC, Holroyd GH, Hetherington AM, Campbell MM: AtMYB61, an R2R3-MYB transcription factor controlling stomatal aperture in Arabidopsis thaliana. Curr Biol 2005, 15:1201-1206.

78. Gupta AK, Gaur VS, Gupta S, Kumar A: Nitrate signals determine the sensing of nitrogen through differential expression of genes involved in nitrogen uptake and assimilation in finger millet. Funct Integr Genomics 2013, 13:179-190.

79. Gupta N, Gupta AK, Kumar A: Spatial distribution pattern analysis of Dof1 transcription factor in different tissues of three Eleusine coracana genotypes differing in their grain protein, yield and photosynthetic efficiency. Mol Biol Rep 2011, 39:2089-2095.

80. Yanagisawa S, Akiyama A, Kisaka H, Uchimiya H, Miwa T: Metabolic engineering with Dof1 transcription factor in plants: improved nitrogen assimilation and growth under low- nitrogen conditions. Proc Natl Acad Sci 2004, 101:7833-7838.

doi:10.1186/1471-2229-14-111

Cite this article as: Song et al:: Effects of high temperature on

photosynthesis and related gene expression in poplar. BMC Plant Biology 2014 14:111.

\section{Submit your next manuscript to BioMed Central and take full advantage of:}

- Convenient online submission

- Thorough peer review

- No space constraints or color figure charges

- Immediate publication on acceptance

- Inclusion in PubMed, CAS, Scopus and Google Scholar

- Research which is freely available for redistribution 